\title{
Gadolinium-free Magnetic Resonance Imaging of the Liver using an Oatp1-targeted Manganese(III) Porphyrin
}

Nivin N. Nyström ${ }^{\#, 1,2}$, Hanlin Liü,3,4, Francisco M. Martinez ${ }^{2}$, Xiao-an Zhang ${ }^{*}, 3,4$, Timothy J. Scholl ${ }^{1,2,5}$, and John A. Ronald ${ }^{*}, 1,2,6$

1. Department of Medical Biophysics, University of Western Ontario, London, ON, Canada.

2. Imaging Research Laboratories, Robarts Research Institute, Western University, London, ON, Canada.

3. Department of Chemistry, University of Toronto, Toronto, ON, Canada.

4. Department of Physical and Environmental Sciences, University of Toronto, Toronto, ON, Canada

5. Ontario Institute for Cancer Research, Toronto, ON, Canada.

6. Lawson Health Research Institute, London, ON, Canada

${ }^{\#}$ These authors contributed equally to this work.

*Correspondence should be addressed to X.a.Z. (xiaoan.zhang@utoronto.ca) and J.A.R. (jronald@robarts.ca).

\section{ABSTRACT}

Controversy surrounding gadolinium-based contrast agents (GBCAs) have rendered their continued utility highly contentious, but the liver-specific GBCA Gd(III) ethoxybenzyl-diethylene triamine pentaacetic acid (Gd(III)-EOB-DTPA) remains in use because it provides unique diagnostic information that could not be obtained by any other means. To address the need for an alternative liver-specific MRI contrast agent, we synthesized Mn(III) 20-(4-ethoxyphenyl) porphyrin-5,10,15-tricarboxylate (Mn(III)TriCP-PhOEt), which exhibited significantly higher $r_{1}$ relaxivity than $\mathrm{Gd}(\mathrm{III})$-EOB-DTPA, and targeted organic anion-transporting polypeptide 1 (Oatp1) channels as a biomarker of hepatocyte viability. Mn(III)TriCP-PhoEt increased the $r_{1}$ relaxation rate of cells expressing rodent Oatplal and human Oatp1b3, relative to control cells not expressing these liver channels. In mice, Mn(III)TriCP-PhoEt resulted in significant and specific increases in liver signal intensity on $T_{1}$-weighted images, and significant decreases in liver $T_{1}$ time relative to precontrast measurements. Our findings suggest that $\mathrm{Mn}$ (III)TriCP-PhOEt operates as a specific and sensitive MR contrast agent for in vivo liver imaging.

\section{Keywords}

Gadolinium, Manganese, MRI, Oatp1, Porphyrin, Liver Imaging, Contrast Agents 


\section{INTRODUCTION}

Magnetic resonance imaging (MRI) is widely applied for clinical diagnosis of disease by generating detailed high-resolution, 3-dimensional images of deep tissues in living subjects. Native image contrast is derived from the magnetic relaxation properties and distribution of abundant water protons $\left({ }^{1} \mathrm{H}\right)$ in soft tissues. In addition, contrast agents can be used to shorten the longitudinal $\left(T_{1}\right)$ or transverse $\left(T_{2}\right)$ nuclear spin relaxation time of bulk water protons, and in turn, increase the contrast of tissues, vessels, cells or molecular events that would otherwise go undetected with non-contrast ${ }^{1} \mathrm{H}$ MRI. In the clinic, gadolinium-based contrast agents (GBCAs) are administered in approximately $40 \%$ of patient scans tens of millions of times annually. ${ }^{[1]}$ GBCAs have provided essential diagnostic information that often cannot be obtained by other noninvasive modalities, making them highly beneficial.

No safety concerns existed with the use of GBCAs until 2006, when a seminal study ${ }^{[2]}$ linked Gd(III) exposure to the onset of a debilitating and sometimes fatal disease called nephrogenic systemic fibrosis (NSF), the first cases of which surfaced in 1997. ${ }^{[3]}$ With identification of severe renal impairment as a major risk factor for NSF, limiting access of GBCAs to patients with low glomerular filtration rates has reduced cases to single digits. ${ }^{[4]}$ More recently however, GBCAs have received scrutiny due to the discovery of long-term deposition in the central nervous system, liver, skin and bone of patients with otherwise healthy kidneys. This has been particularly evident in patients that received multiple doses of GBCAs where concentrations of retained $\mathrm{Gd}(\mathrm{III})$ in tissues rose above millimolar detection thresholds on MR images. ${ }^{[5]}$ Beyond the clinic, GBCAs are also emerging as environmental contaminants in aquatic ecosystems, especially in locations surrounding major medical hubs. ${ }^{[6]}$

Various approaches have been pursued to address concerns associated with GBCAs, including chelation therapies administered after image acquisition ${ }^{[7]}$ and artificial intelligencebased methods that create synthetic contrast-enhanced images, ${ }^{[8]}$ but while these are in early stages of development, Gd(III)-free contrast agents remain the most reliable method for generating contrast enhancement without GBCA-associated risks. ${ }^{[1]}$ Contrast enhancement on MRI can be achieved by various other compounds including manganese-based contrast agents (MBCAs), superparamagnetic iron oxide nanoparticles (SPIONs), exchangeable solute protons for chemical exchange saturation transfer (CEST) imaging, X-nuclei for non-proton MRI, and hyperpolarized imaging. ${ }^{[9]}$ Of these, MBCAs generate $T_{1}$-weighted contrast with in vivo kinetics and biodistributions most like GBCAs, and do not require specialized pulse sequences, further postprocessing, or auxiliary hardware. ${ }^{[9]}$ Collectively, these aspects render MBCAs as attractive alternatives to GBCAs for contrast-enhanced MRI.

Notably, in vitro and animal studies have demonstrated that linear GBCAs in particular exhibit increased risks due to decreased chelation stabilities and increased tissue retention rates relative to macrocyclic GBCAs. ${ }^{[10]}$ In 2017, the U.S. Food and Drug Administration (FDA) announced a class warning for all GBCAs ${ }^{[11]}$ and the European Medicines Agency (EMA) followed ${ }^{[12]}$ by suspending marketing authorizations for three of the five GBCAs comprised of linear chelators as the "benefit-risk balance [was] no longer favorable." During these announcements however, $\mathrm{Gd}(\mathrm{III})$ ethoxybenzyl-diethylene triamine pentaacetic acid (Gd(III)EOB-DTPA; Gadoxetic acid, Gadoxetate disodium, Primovist ${ }^{\circledR}$, Eovist ${ }^{\circledR}$, Bayer HealthCare 
Pharmaceuticals, Leverkusen, Germany) remained available for liver imaging despite its linearity because it "met an important diagnostic need" without which, differential diagnosis could not be ascertained. ${ }^{[12]}$

MBCA alternatives for GBCAs, including Gd(III)-EOB-DTPA, have previously been explored, but these typically consist of $\mathrm{Mn}(\mathrm{II}), q=1$ complexes that exhibit lower relaxivities relative to their GBCA counterparts, thereby requiring administration of higher doses to generate sufficient contrast enhancement. ${ }^{[13]}$ For instance, mangafodipir trisodium (MnDPDP) was designed as a gadolinium-free substitute for liver imaging but required two to four multiples $(0.05-0.1 \mathrm{mmol} / \mathrm{kg})$ of an already large dose of Gd(III)-EOB-DTPA $(0.025 \mathrm{mmol} / \mathrm{kg})$ to provide sufficient liver contrast in patients. ${ }^{[14]}$ Notwithstanding, optimization of the chemical chelator and structure chelating the paramagnetic center can improve relaxivity to generate nextgeneration Gd(III)-free contrast agents that outperform their GBCA counterparts.

More specifically, Gd(III)-EOB-DTPA generates targeted contrast in the liver through uptake by organic anion-transporting polypeptide 1 (Oatp1) proteins that are expressed on the membranes of human hepatocytes, namely Oatp1b1 and Oatp1b3. ${ }^{[15]}$ The absence of these proteins, indicated by low enhancement following Gd(III)-EOB-DTPA administration, thereby allows for detection and characterization of metastases in the liver, nodular lesions of cirrhosis, as well as quantitative assessment of liver perfusion and hepatocyte function in diffuse liver diseases. ${ }^{[16]}$ In the preclinical context, Gd(III)-EOB-DTPA provides liver contrast through uptake via the rat and murine ortholog transporter, named Oatplal for both species. ${ }^{[17]}$ Beyond endogenous expression for liver imaging, this protein-ligand pair has been developed as an MRI reporter gene system, although its Gd(III)-based probe is identified as a limitation to its clinical translation for in vivo tracking of gene- and cell-based therapies in patients. ${ }^{[18]}$

Here we sought to develop an Oatp1-targeted MBCA with high relaxivity. We based our contrast agent design on a porphyrin ligand, which consists of four pyrroles that altogether make up a large octahedral ring molecule, chelated to a high spin $(S=2)$ manganese(III) center (Figure 1). Previously, combining the electron-spin properties of $\mathrm{Mn}(\mathrm{III})$ paramagnetic label with the rigid, geometrically flat porphyrin chelator allowed for water coordination both above and below the plane of the molecule $(q=2)$, resulting in increased relaxivity without sacrificing thermodynamic stability ${ }^{[19]}$. Curiously, Mn(III)Ps also stray in behavior from GBCAs and other $\mathrm{Mn}(\mathrm{II})$ agents by exhibiting an increase in relaxivity above field strengths of $2 \mathrm{MHz}$ instead of a steep decline, ${ }^{[20]}$ further compelling us to employ this structure for Oatp1 imaging. To address the need for an Oatp1-specific Gd(III)-free contrast agent without compromising relaxation efficiency, we designed and synthesized Mn(III) 20-(4-ethoxyphenyl)porphyrin-5,10,15tricarboxylate (Mn(III)TriCP-PhOEt). We report its superiority to Gd(III)-EOB-DTPA with respect to relaxivity at clinical field strengths, demonstrate its specificity as an MR probe for Oatplal and Oatplb3 transporters, as well as its effectiveness for in vivo contrast-enhanced liver imaging in mice. 


\section{RESULTS}

Synthesis of Mn(III)TriCP-PhOEt. Manganese (III) 20-(4-ethoxyphenyl)porphyrin-5,10,15tricarboxylate (Mn(III)TriCP-PhOEt) was synthesized using an acid catalyzed condensation reaction between aldehydes and pyrrole (Figure 2A). Complete details of synthesis procedures and instrumentation are located in Supporting Information. All generated compounds were validated with ESI-MS and/or ${ }^{1} \mathrm{H}$ NMR (Supplementary Figures 1-4). The synthetic precursors, $\alpha-1 H$-pyrrol-2-yl-1H-pyrrole-2-acetic acid ethyl ester (EDP) and 2,2'-(4ethoxyphenylmethylene)bis-1H-pyrrole (DPM-PhOEt) were produced at $79 \%$ and $67.9 \%$ yield, respectively. Coupling of EDP and DPM-PhOEt gave triethyl 20-(4-ethoxyphenyl)porphyrin5,10,15-tricarboxylate (TriEP-PhOEt) at 23\% yield (484.5 mg). Upon metal-insertion, manganese (III) triethyl 20-(4-ethoxyphenyl)porphyrin-5,10,15-tricarboxylate (MnTriEP-PhOEt) was produced at $46.6 \%$ yield which was then hydrolyzed to generate final product, Mn(III)TriCPPhOEt at $82.7 \%$ yield. ESI-MS of Mn(III)TriCP-PhOEt found a mass-to-charge ratio $(\mathrm{m} / \mathrm{z})$ of $306.1\left([\mathrm{M}]^{2-}\right.$ ), in close agreement with the $\mathrm{m} / z$ calculated for $\mathrm{C}_{31} \mathrm{H}_{17} \mathrm{MnN}_{4} \mathrm{O}_{7}^{2-}$ of 306.03 (Figure 2B). TriEP-PhOEt, Mn(III)TriEP-PhOEt, and Mn(III)TriCP-PhOEt exhibited unique peaks on UV-Vis spectra at $414 \mathrm{~nm}, 460 \mathrm{~nm}$, and $467 \mathrm{~nm}$, respectively (Figure 2C). Dominant peak of Mn(III)TriCP-PhOEt on HPLC-UV exhibited 97.8\% purity (Figure 2D).

\section{Mn(III)TriCP-PhOEt exhibits increased $\boldsymbol{r}_{1}$ relaxivity relative to Gd(III)-based contrast} agents. Nuclear magnetic relaxation dispersion (NMRD) profiles were acquired at $B_{0} \in(0,1) \mathrm{T}$ field strengths, $1 \mathrm{mM}$ concentrations, and $37^{\circ} \mathrm{C}$ temperatures using a Spinmaster fast fieldcycling relaxometer (Stelar s.r.1, Mede Italy). The relaxivities of Gd(III)-DTPA and Gd(III)EOB-DTPA acquired were in agreement with literature values. ${ }^{[21]}$ At low fields, where $B_{0}<$ $0.01 \mathrm{~T}$, all three contrast agents exhibited linear $r_{1}$ relaxivities with respect to variable field strength. For $B_{0} \in(0,0,01) \mathrm{T}$, the mean average $r_{1}$ relaxivity for Gd(III)-DTPA was $7.817 \pm$ $0.068 \mathrm{mmol}^{-1} \mathrm{~s}^{-1}, 9.955 \pm 0.087 \mathrm{mmol}^{-1} \mathrm{~s}^{-1}$ for Gd(III)-EOB-DTPA, and $5.911 \pm 0.037 \mathrm{mmol}^{-1} \mathrm{~s}^{-1}$ for Mn(III)TriCP-PhOEt (Figure 3A). At $0.01<B_{0}<1 \mathrm{~T}$, the $r_{1}$ relaxivity of both GBCAs decreases to $4.763 \pm 0.042 \mathrm{mmol}^{-1} \mathrm{~s}^{-1}$ for Gd(III)-DTPA, and $7.330 \pm 0.045 \mathrm{mmol}^{-1} \mathrm{~s}^{-1}$ for $\mathrm{Gd}(\mathrm{III})-\mathrm{EOB}-\mathrm{DTPA}$. However, across this same range, the $r_{1}$ relaxivity of $\mathrm{Mn}$ (III)TriCP-PhOEt increases and surpasses that of Gd(III)-DTPA at $0.1 \mathrm{~T}$ and that of Gd(III)-EOB-DTPA at $0.18 \mathrm{~T}$, reaching a maximum of $8.942 \pm 0.091 \mathrm{mmol}^{-1} \mathrm{~s}^{-1}$ at $0.425 \mathrm{~T}$ before decreasing marginally to $8.794 \pm 0.071 \mathrm{mmol}^{-1} \mathrm{~s}^{-1}$ at $1 \mathrm{~T}$ (Figure 3A). Inversion recovery experiments $(\mathrm{n}=3)$ were performed at $1.5 \mathrm{~T}$ on a clinical MRI system at $18^{\circ} \mathrm{C}$ to calculate relaxivities at those field strengths. At $1.5 \mathrm{~T}, \mathrm{Mn}(\mathrm{III}) \mathrm{TriCP}-\mathrm{PhOEt}$ displays a significantly higher relaxivity $(8.32 \pm 0.21$ $\left.\mathrm{mmol}^{-1} \mathrm{~s}^{-1}\right)$ than both Gd(III)-DTPA $\left(4.66 \pm 0.34 \mathrm{mmol}^{-1} \mathrm{~s}^{-1}, 56.02 \%\right.$ of $\left.r_{1 \mathrm{MnTriCP}-\mathrm{PhOE}}, \mathrm{p}<0.0001\right)$

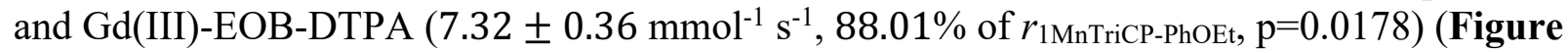
3A). At $3 \mathrm{~T}, \mathrm{Mn}(\mathrm{III}) \mathrm{TriCP}-\mathrm{PhOEt}$ also displays a significantly higher relaxivity $(11.25 \pm 0.35$ $\left.\mathrm{mmol}^{-1} \mathrm{~s}^{-1}\right)$ than Gd(III)-DTPA $\left(6.20 \pm 0.18 \mathrm{mmol}^{-1} \mathrm{~s}^{-1}, 55.11 \%\right.$ of $\left.r_{1 \text { MnTriCP-PhOEt, }} \mathrm{p}<0.0001\right)$ and Gd(III)-EOB-DTPA $\left(8.34 \pm 0.23 \mathrm{mmol}^{-1} \mathrm{~s}^{-1}, 74.13 \%\right.$ of $\left.r_{1 \mathrm{MnTriCP}-P h O E t}, \mathrm{p}<0.0001\right)$ (Figure 3B).

Cells expressing Oatp1a1/1b3 transporters exhibit increased $r_{1}$ relaxivity when treated with Mn(III)TriCP-PhOEt. Rat C6 glioma cells and human triple negative breast cancer MDA-MB231 cells were engineered with lentivirus to express Oatp1a1 with tdTomato and Oatp1b3 with zsGreen, respectively (Figure 4A, 4B). Cells were sorted with fluorescent activated cell sorting (FACS) resulting in an engineered cell population with $>99 \%$ purity (Figure 4C, 4D). Control and 
transporter-expressing cells were treated in suspension with $\mathrm{Mn}(\mathrm{III}) \mathrm{TriCP}-\mathrm{PhOEt}$, Gd(III)-EOBDTPA, or Gd(III)-DTPA, subsequently washed, trypsinized and pelleted for $R_{1}$ measurements at $3 \mathrm{~T}(\mathrm{n}=3)$. As a control, naive and transporter-expressing cells did not exhibit differences in spinlattice relaxation rates $(\mathrm{Hz})$ when incubated with $1-\mathrm{mM} \mathrm{Gd}(\mathrm{III})$-DTPA, which is not permeable to the cell membrane, and is not recognized as a ligand by either Oatp1a1 or Oatp1b3 transporters (Figure 4E, first column). Additionally, control cells not expressing Oatp1a1 or Oatp1b3 transporters did not exhibit differences in relaxivity when treated with either Gd(III)-DTPA, Gd(III)-EOB-DTPA, or Mn(III)TriCP-PhOEt, confirming that all three contrast agents are impermeable to cell membranes in the absence of Oatp1a1 or Oatp1b3 transporters (Figure 4E, first row). For the rat Oatpla1 transporter, treatment with Mn(III)TriCP-PhOEt resulted in an increased spin-lattice relaxation rate $(2.76 \pm 0.38 \mathrm{~Hz})$ relative to Oatpla1-expressing cells treated with Gd(III)-EOB-DTPA $(2.50 \pm 0.36 \mathrm{~Hz})$, albeit this difference was not statistically significant $(\mathrm{p}=0.845)$ (Figure 4E, 4F). For the human Oatp1b3 transporter, cells treated with Mn(III)TriCPPhOEt exhibited a significantly increased spin-lattice relaxation rate $(2.24 \pm 0.13 \mathrm{~Hz})$ relative to the same cells treated with Gd(III)-EOB-DTPA $(1.52 \pm 0.03 \mathrm{~Hz}, \mathrm{p}=0.0429)$ (Figure 4E, 4F).

Mn(III)TriCP-PhOEt enables in vivo contrast enhancement of liver tissue at clinical doses. As a control, manganese(III) porphyrin-5,10,15,20-tetracarboxylate (MnTCP), which is structurally related to $\mathrm{Mn}$ (III)TriCP-PhOEt barring the presence of a fourth carboxylic acid functional group in place of the PhOEt moiety, exhibited significant contrast enhancement in the kidneys, but virtually no $T_{1}$-shortening effects in liver tissue (Supplementary Figure 5) analogous to Gd(III)-DTPA, and in agreement with previous Mn(III)TCP biodistribution findings. ${ }^{[22]}$ Upon intraperitoneal injection of $0.025 \mathrm{mmol} / \mathrm{kg} \mathrm{Mn}(\mathrm{III})$ TriCP-PhOEt, contrast enhancement was observed for $T_{1}$-weighted images of the liver and gallbladder as part of the hepatobiliary system and the kidneys and bladder as part of the renal system (Figure 5A). On average across all mice $(\mathrm{n}=4)$, a significant increase in liver signal intensity (arbitrary units, a.u.) was observed between pre-contrast images and post-contrast images acquired greater than 28 minutes following intraperitoneal injection of $0.025 \mathrm{mmol} / \mathrm{kg} \mathrm{Mn}$ (III)TriCP-PhOEt (171.2 $\pm 39.6 \%, \mathrm{p}=0.031)$, which continued to increase until a maximal increase in liver signal intensity (a.u.) of $191.4 \pm 37.3 \%$ was observed at the 52-minute imaging timepoint $(\mathrm{p}=0.014)$ (Figure 5B). The average area under the curve (AUC) within a 60-minute imaging course $(n=3)$ between the liver (29,298 \pm 1639 a.u.) and kidney volumes $(30,442 \pm 758$ a.u. $)$ were not significantly different $(p=0.607)$, but both were significantly higher than the average AUC of the heart $(12,087 \pm 1642$ a.u., $\mathrm{p}<0.0001)$ (Figure 5C, 5D). The $\mathrm{AUC}_{\text {liver }}$ to $\mathrm{AUC}_{\text {kidney }}$ ratio of 1.00 to 1.04 suggests that the percentage of $\mathrm{Mn}(\mathrm{III})$ TriCP-PhOEt clearance by organ is relatively equal between the hepatobiliary and renal systems.

Quantitative $\boldsymbol{R}_{1}$ mapping increases liver imaging sensitivity and specificity of Mn(III)TriCPPhOEt relative to $\boldsymbol{T}_{\mathbf{1}}$-weighted imaging. In addition to dynamic contrast enhanced $T_{1}$-weighted imaging, dynamic contrast enhanced quantitative imaging was performed to measure in vivo changes in spin-lattice relaxation rates before and up to an hour following $0.025 \mathrm{mmol} / \mathrm{kg}$ $\mathrm{Mn}$ (III)TriCP-PhOEt administration (Figure 5E). Whereas significant differences in liver signal intensity on $T_{1}$-weighted images were observed 28 minutes after administration, significantly lower $T_{1}$ values of liver tissue was observed as early as 12 minutes post administration (598.5 \pm $52.9 \mathrm{~ms}, \mathrm{p}=0.012)$ relative to the $T_{1}$ time of the liver precontrast $(798.5 \pm 16.9 \mathrm{~ms})$ (Figure 5F). Moreover, the average percent standard deviation of liver signal intensity on $T_{1}$-weighted images 
$(19.02 \pm 4.3 \%)$ was significantly greater than the average percent standard deviation of liver spinlattice relaxation rates observed on $R_{1}$ maps $(7.06 \pm 2.1 \%, \mathrm{p}=0.010)$. This increased precision in the latter method enables more sensitive detection of changes relative to pre-contrast images. Slight decreases in $T_{1}$ times were observed for both kidney and heart tissue but no significant differences were observed for either tissue at any timepoint during the 60-minute course of imaging, relative to precontrast values, even after segmenting each organ into independent compartments e.g. renal medulla, renal cortex, heart walls, heart chambers.

Ex vivo nuclear magnetic relaxation dispersion confirms spin-lattice relaxation rate differences are liver-specific. Mice $(n=3)$ were intraperitoneally injected with either saline or $0.025-\mathrm{mmol} / \mathrm{kg} \mathrm{Mn}$ (III)TriCP-PhOEt and sacrificed 36 minutes post administration. Liver, kidney and muscle tissue was harvested and NMRD was performed for each tissue sample. Significant differences in spin-lattice relaxation times were observed specifically between liver tissue of $\mathrm{Mn}$ (III)TriCP-PhOEt and control mice at $0.3<B_{0}<1 \mathrm{~T}(\mathrm{p}<0.05$, Figure 6A), which is not unexpected given that the relaxivity of $\mathrm{Mn}$ (III)TriCP-PhOEt decreases drastically at field strengths lower than this range (Figure 3A). Following the same finding observed in vivo at $3 \mathrm{~T}$ however (Figure 5F), no significant differences were observed at $0.01<B_{0}<1 \mathrm{~T}$ for either kidney or muscle tissue between $\mathrm{Mn}$ (III)TriCP-PhOEt and control tissue samples (Figure 3A). The maximal difference in spin-lattice relaxation rate was $0.679 \mathrm{~Hz}$ for liver tissue at $B_{0}=0.3057 \mathrm{~T}, 0.452 \mathrm{~Hz}$ for kidney tissue at $B_{0}=0.0154 \mathrm{~T}$, and $0.297 \mathrm{~Hz}$ for muscle tissue at $B_{0}=0.0154 \mathrm{~T}$. 


\section{DISCUSSION}

In response to increased evidence of long-term tissue retention, a new class warning for all GBCAs was announced by the FDA in $2017^{[11]}$ and the European Medicines Agency (EMA) followed by suspending marketing authorizations for three of the five GBCAs comprised of linear chelators due to their increased susceptibility to release $\mathrm{Gd}(\mathrm{III}) \cdot{ }^{[12]}$ However, Gd(III)-EOB-DTPA remained available for liver imaging because it provided unique diagnostic information that could not be obtained by alternative methods. ${ }^{[12]}$ Here, we demonstrate that Mn(III) 20-(4ethoxyphenyl)porphyrin-5,10,15-tricarboxylate (Mn(III)TriCP-PhOEt) offers high specificity and high sensitivity for Oatpl-targeted imaging in vivo, which enables contrast-enhanced liver imaging on $\mathrm{MR}^{[15]}$ and paves the path towards Oatp1 reporter gene imaging ${ }^{[18 \mathrm{a}, 18 \mathrm{c}, 23]}$ without the need to include Gd(III) in the protocol or sacrifice relaxivity (Figure 1).

First, the Mn(III)TriCP-PhOEt complex was shown to have superior $r_{1}$ relaxivity at 1.5 Tesla, and even more so, at 3 Tesla, relative to that of Gd(III)-EOB-DTPA (Figure 3). Next, we demonstrated the specificity of its uptake through the rodent Oatplal and human Oatplb3 transporters using cells genetically engineered to synthetically express these proteins. The $\mathrm{Mn}$ (III)TriCP-PhOEt complex again outperformed the contemporary Gd(III)-EOB-DTPA probe, with respect to resultant $r_{1}$ relaxivities of Oatp1-expressing cells incubated with each respective agent (Figure 4). Finally, uptake of $\mathrm{Mn}(\mathrm{III})$ TriCP-PhOEt in vivo by murine liver cells that endogenously express Oatplal was demonstrated via significant increases in liver signal intensity following low-dose intraperitoneal injections $(0.025 \mathrm{mmol} / \mathrm{kg})$ of $\mathrm{Mn}(\mathrm{III})$ TriCP-PhOEt (Figure 5A-D).

Dynamic $R_{1}$ mapping at 3 Tesla was additionally performed to quantify $T_{1}$-shortening effects following $\mathrm{Mn}$ (III)TriCP-PhOEt administration, and $T_{1}$-shortening in the liver was significantly more pronounced relative to the kidneys (Figure 5E, 5F). Although this was in discordance with the almost equivalent increases in signal intensity observed in the liver and kidneys on $T_{1}$-weighted images, this finding was further confirmed by ex vivo NMRD measurements (Figure 6) and is likely due to the considerable variation in $T_{1}$ values within the kidney volume as a reflection of its complex structure, ${ }^{[24]}$ and despite efforts to delineate individual renal compartments, the large variation in kidney $T_{1}$ time persisted. Altogether, these findings support Mn(III)TriCP-PhOEt as an effective contrast agent for liver imaging on MR.

One immediate point of improvement, however, will be to increase the relatively low aqueous solubility of the complex, which was found to saturate at about $1.6 \mathrm{mM}$ concentrations in saline at $37^{\circ} \mathrm{C}$. Despite basing the design of this $\mathrm{Mn}$ (III)P on a less established anionic parent with carboxylic acid moieties at its periphery, ${ }^{[22]}$ with the notion that solubility would not present as an issue in animal studies, the overall aromatic structure of the porphyrin as well as the addition of the Oatpla1/1b3-specific phenyloxy ethyl ligand contributed sufficiently to its hydrophobicity. This was mitigated to some extent by dissolving Mn(III)TriCP-PhOEt in dimethyl sulfoxide (DMSO) before further dilution in saline prior to injection.

Yet even when dissolved in organic solvents, intravenous injections were not feasible considering the volume of injection required, thereby warranting intraperitoneal administrations in our animal studies, which non-negligibly reduced the bioavailability of the contrast agent in the 
blood. ${ }^{[25]}$ Despite this, significant increases in the mean signal intensity and $R_{1}$ rates of the liver volume were observed in mice, probably owed to the high $r_{1}$ relaxivity of Mn(III)TriCP-PhOEt. We anticipate that improving solubility to enable intravenous injections in animals would further amplify contrast enhancement, though the human equivalent dose, which is typically more than 10 -fold smaller than that of rodent animal models, ${ }^{[26]}$ may be small enough to already permit intravenous injections in patients without the need to increase solubility.

Overall, Mn(III)Ps offer a unique combination of advantages as MRI contrast agents. $\mathrm{Mn}$ (III)Ps have been established as thermodynamically stable and kinetically inert, but even so, manganese, unlike Gd(III), is a nutritional element that the human body is able to physiologically incorporate or excrete, thereby evading concerns of long-term accumulation and subsequent toxicity. ${ }^{[27]}$ In extreme cases, Mn ion exposure has been associated with a neurodegenerative disorder called manganism, but a large cumulative amount of free $\mathrm{Mn}$ (over $3.8 \mathrm{mmol} / \mathrm{kg}$ ) is required to induce toxicity, unlikely to be achieved even after repeat $\mathrm{Mn}(\mathrm{III}) \mathrm{P}$ doses. ${ }^{[28]}$ In fact, manganese enhanced MRI (MEMRI) studies, whereby small doses of free Mn are administered directly to preclinical animals, is routinely used to map neural activity. ${ }^{[29]}$ Even in humans, Mn(II)-DPDP by design operated on the mechanism of Mn ion release, and was clinically assessed as having a safety factor ( $\mathrm{LD}_{50}$ /effective dose) of 540, significantly greater than that of GBCAs that have safety factors ranging from 60 to $100 .^{[30]}$ For our own work, future studies will focus on developing a more soluble Oatpl-targeted $\mathrm{Mn}(\mathrm{III}) \mathrm{P}$ and characterizing its kinetic and thermodynamic stability as well as assessing its performance in detecting liver metastasis in mice and engineered cells for reporter gene tracking.

Mn(III)Ps have been extensively studied in vitro ${ }^{[19]}$ though the precise mechanics dictating their "anomalously" high relaxivity are less deeply explored than those of Gd(III) and Mn(II), owing to the unusual electron spin behaviors and strong metal-ligand orbital interactions. ${ }^{[20,31]}$ Early in vivo imaging studies have focused on Mn(III)Ps as vascular agents, and more recently, works have expanded functions of Mn(III)Ps for extracellular, intracellular and intravascular applications. ${ }^{[27,32]}$ The next generation of contrast agents will have high tissue specificity and/or the ability to act as reporters of the environment in which they are distributed. With four distinct modification sites at the porphyrin meso-positions, $\mathrm{Mn}$ (III)Ps will be exceptionally suited to facilitate these efforts. In fact, oxygen, ${ }^{[33]}$ zinc, ${ }^{[19]}$ calcium, ${ }^{\left[{ }^{[3]}\right.}$ secreted alkaline phosphatase, ${ }^{[35]}$ and esterase-responsive ${ }^{[36]} \mathrm{Mn}(\mathrm{III}) \mathrm{Ps}$ have already been reported. Historically, GBCAs have shown tremendous utility and have single-handedly enabled contrast enhanced MR imaging in patients for many years, but as more insight into their retention in patients' bodies and the environment is revealed, their continued use loses justification, especially as contrast agents that are both safer and better-performing arise.

\section{CONCLUSION}

Our study finds that Mn(III) 20-(4-ethoxyphenyl)porphyrin-5,10,15-tricarboxylate (MnTriCP-PhOEt) exhibits superior $r_{1}$ relaxivity relative to Gd(III)-EOB-DTPA at clinicallyrelevant field strengths and demonstrates specificity to rodent Oatpla1 and human Oatp 1b3 channels as biomarkers of hepatocyte viability. In mice, $0.025 \mathrm{mmol} / \mathrm{kg}$ injections of $\mathrm{Mn}(\mathrm{III})$ TriCP-PhOEt enhance liver contrast with high sensitivity and specificity in 3-dimensions. 
Mn(III)TriCP-PhOEt offers a new approach for liver imaging on MRI without the need to administer gadolinium to patients or sacrifice sensitivity.

\section{ACKNOWLEDGEMENTS}

Financial support for this manuscript was provided by Natural Sciences and Engineering Research Council (NSERC) Discovery Grants (J.A.R. RGPIN-2016-05420, T.J.S. RGPIN-201706338, and X.A.Z. RGPIN-2016-489075), Ontario Institute for Cancer Research Investigator Award (T.J.S. IA-028) and Canadian Institutes of Health Research Project Grant (J.A.R. 377071). X.A.Z. is also grateful to the University of Toronto Scarborough, Canada Foundation for Innovation, and Ontario Research Fund for their support. This work was additionally supported by the Breast Cancer Society of Canada (N.N.N.), and an NSERC Postgraduate Doctoral Scholarship (N.N.N.).

\section{CONFLICTS OF INTEREST}

The authors declare no potential conflicts of interest. 


\section{REFERENCES}

[1] J. Wahsner, E. M. Gale, A. Rodriguez-Rodriguez, P. Caravan, Chem Rev 2019, 119, 9571057.

[2] T. Grobner, Nephrol Dial Transplant 2006, 21, 1104-1108.

[3] S. E. Cowper, Curr Opin Rheumatol 2003, 15, 785-790.

[4] aH. Attari, Y. Cao, T. R. Elmholdt, Y. Zhao, M. R. Prince, Radiology 2019, 292, 376386; bM. S. Davenport, Radiology 2019, 292, 387-389.

[5] aT. Kanda, K. Ishii, H. Kawaguchi, K. Kitajima, D. Takenaka, Radiology 2014, 270, 834841; bR. J. McDonald, J. S. McDonald, D. F. Kallmes, M. E. Jentoft, D. L. Murray, K. R. Thielen, E. E. Williamson, L. J. Eckel, Radiology 2015, 275, 772-782; cR. J. McDonald, J. S. McDonald, D. F. Kallmes, M. E. Jentoft, M. A. Paolini, D. L. Murray, E. E. Williamson, L. J. Eckel, Radiology 2017, 285, 546-554.

[6] aV. Hatje, K. W. Bruland, A. R. Flegal, Environ Sci Technol 2016, 50, 4159-4168; bW. Gwenzi, L. Mangori, C. Danha, N. Chaukura, N. Dunjana, E. Sanganyado, Sci Total Environ 2018, 636, 299-313; cR. Brunjes, T. Hofmann, Water Res 2020, 182, 115966.

[7] aJ. Boyken, T. Frenzel, J. Lohrke, G. Jost, G. Schutz, H. Pietsch, Invest Radiol 2019, 54, 76-82; bJ. A. Rees, G. J. Deblonde, D. D. An, C. Ansoborlo, S. S. Gauny, R. J. Abergel, Sci Rep 2018, 8, 4419.

[8] aA. S. Lundervold, A. Lundervold, Z Med Phys 2019, 29, 102-127; bE. Gong, J. M. Pauly, M. Wintermark, G. Zaharchuk, J Magn Reson Imaging 2018, 48, 330-340; cP. A. Narayana, I. Coronado, S. J. Sujit, J. S. Wolinsky, F. D. Lublin, R. E. Gabr, Radiology 2020, 294, 398-404.

[9] J. Lux, A. D. Sherry, Curr Opin Chem Biol 2018, 45, 121-130.

[10] aG. Jost, T. Frenzel, J. Boyken, J. Lohrke, V. Nischwitz, H. Pietsch, Radiology 2019, 290, 340-348; bT. J. Clough, L. Jiang, K. L. Wong, N. J. Long, Nat Commun 2019, 10 , 1420.

[11] In FDA 2017.

[12] In EMA 2017.

[13] aF. K. Kalman, V. Nagy, B. Varadi, Z. Garda, E. Molnar, G. Trencsenyi, J. Kiss, S. Meme, W. Meme, E. Toth, G. Tircso, J Med Chem 2020, 63, 6057-6065; bD. J. Erstad, I. A. Ramsay, V. C. Jordan, M. Sojoodi, B. C. Fuchs, K. K. Tanabe, P. Caravan, E. M. Gale, Invest Radiol 2019, 54, 697-703.

[14] M. P. Federle, J. L. Chezmar, D. L. Rubin, J. C. Weinreb, P. C. Freeny, R. C. Semelka, J. J. Brown, J. A. Borello, J. K. Lee, R. Mattrey, A. H. Dachman, S. Saini, B. Harmon, M. Fenstermacher, R. E. Pelsang, S. E. Harms, D. G. Mitchell, H. H. Halford, M. W. Anderson, C. D. Johnson, I. R. Francis, J. G. Bova, P. J. Kenney, D. L. Klippenstein, G. S. Foster, D. A. Turner, J Magn Reson Imaging 2000, 12, 186-197.

[15] B. E. Van Beers, C. M. Pastor, H. K. Hussain, J Hepatol 2012, 57, 421-429.

[16] N. F. Smith, W. D. Figg, A. Sparreboom, Expert Opin Drug Metab Toxicol 2005, 1, 429445.

[17] aN. Tsuda, O. Matsui, Radiology 2010, 256, 767-773; bD. D. Shuboni-Mulligan, M. Parys, B. Blanco-Fernandez, C. L. Mallett, R. Schnegelberger, M. Takada, S. Chakravarty, B. Hagenbuch, E. M. Shapiro, Diabetes 2019, 68, 271-280.

[18] aP. S. Patrick, J. Hammersley, L. Loizou, M. I. Kettunen, T. B. Rodrigues, D. E. Hu, S. S. Tee, R. Hesketh, S. K. Lyons, D. Soloviev, D. Y. Lewis, S. Aime, S. M. Fulton, K. M. 
Brindle, Proc Natl Acad Sci U S A 2014, 111, 415-420; bN. N. Nystrom, A. M. Hamilton, W. Xia, S. Liu, T. J. Scholl, J. A. Ronald, Invest Radiol 2019; cJ. J. Kelly, M. SaeeMarand, N. N. Nystrom, M. M. Evans, Y. Chen, F. M. Martinez, A. M. Hamilton, J. A. Ronald, Sci Adv 2021, 7.

[19] X. A. Zhang, K. S. Lovejoy, A. Jasanoff, S. J. Lippard, Proc Natl Acad Sci U S A 2007, 104, 10780-10785.

[20] S. H. Koenig, R. D. Brown, 3rd, M. Spiller, Magn Reson Med 1987, 4, 252-260.

[21] C. Burtea, S. Laurent, L. Vander Elst, R. N. Muller, Handb Exp Pharmacol 2008, 135165.

[22] H. L. Cheng, I. E. Haedicke, W. Cheng, J. Tchouala Nofiele, X. A. Zhang, J Magn Reson Imaging 2014, 40, 1474-1480.

[23] aN. N. Nystrom, A. M. Hamilton, W. Xia, S. Liu, T. J. Scholl, J. A. Ronald, Invest Radiol 2019, 54, 302-311; bN. N. Nystrom, L. C. M. Yip, J. J. L. Carson, T. J. Scholl, J. A. Ronald, Radiol Imaging Cancer 2019, 1, e190035.

[24] M. P. Graham-Brown, A. Singh, J. Wormleighton, N. J. Brunskill, G. P. McCann, J. Barratt, J. O. Burton, G. Xu, BMC Nephrol 2019, 20, 256.

[25] M. W. Tibbitt, J. E. Dahlman, R. Langer, J Am Chem Soc 2016, 138, 704-717.

[26] A. B. Nair, S. Jacob, J Basic Clin Pharm 2016, 7, 27-31.

[27] W. Cheng, I. E. Haedicke, J. Nofiele, F. Martinez, K. Beera, T. J. Scholl, H. L. Cheng, X. A. Zhang, J Med Chem 2014, 57, 516-520.

[28] D. S. Poole, N. Doorenweerd, J. J. Plomp, A. Mahfouz, M. J. T. Reinders, L. van der Weerd, Neuroimage 2017, 147, 1-9.

[29] aH. Lu, Z. X. Xi, L. Gitajn, W. Rea, Y. Yang, E. A. Stein, Proc Natl Acad Sci U S A 2007, 104, 2489-2494; bX. Yu, Y. Z. Wadghiri, D. H. Sanes, D. H. Turnbull, Nat Neurosci 2005, 8, 961-968.

[30] G. Elizondo, C. J. Fretz, D. D. Stark, S. M. Rocklage, S. C. Quay, D. Worah, Y. M. Tsang, M. C. Chen, J. T. Ferrucci, Radiology 1991, 178, 73-78.

[31] N. Schaefle, R. Sharp, J Phys Chem A 2005, 109, 3267-3275.

[32] H. Liu, Zhang, X.A., Encyclopedia of Inorganic and Bioinorganic Chemistry 2018, eibc2626.

[33] S. Aime, M. Botta, E. Gianolio, E. Terreno, Angew Chem Int Ed Engl 2000, 39, 747-750.

[34] A. Barandov, B. B. Bartelle, C. G. Williamson, E. S. Loucks, S. J. Lippard, A. Jasanoff, Nat Commun 2019, 10, 897.

[35] G. G. Westmeyer, Y. Emer, J. Lintelmann, A. Jasanoff, Chem Biol 2014, 21, 422-429.

[36] I. E. Haedicke, T. Li, Y. L. K. Zhu, F. Martinez, A. M. Hamilton, D. H. Murrell, J. T. Nofiele, H. M. Cheng, T. J. Scholl, P. J. Foster, X. A. Zhang, Chem Sci 2016, 7, 43084317.

[37] S. C. Deoni, T. M. Peters, B. K. Rutt, Magn Reson Med 2005, 53, 237-241.

[38] P. A. Yushkevich, J. Piven, H. C. Hazlett, R. G. Smith, S. Ho, J. C. Gee, G. Gerig, Neuroimage 2006, 31, 1116-1128. 


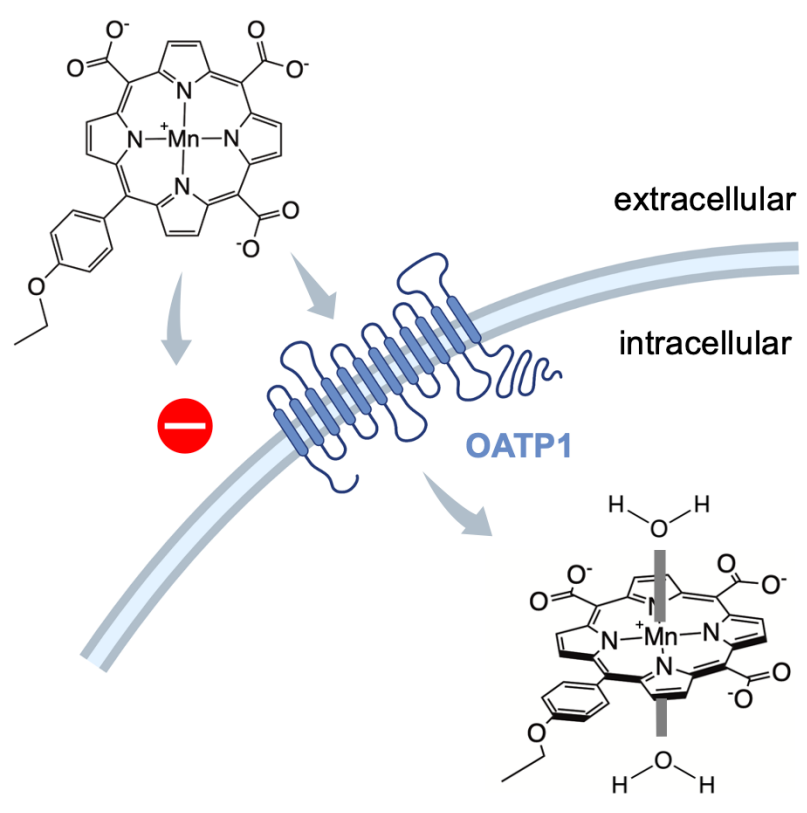

Figure 1. Oatp1-mediated Transport of Mn(III)TriCP-PhOEt for Targeted Magnetic Resonance Imaging. Cellular membranes are impermeable to $\mathrm{Mn}$ (III)TriCP-PhOEt. However, Oatp1a1 (rat) and/or Oatp1b3 (human) transporters that are natively expressed on hepatocytes recognize $\mathrm{Mn}(\mathrm{III})$ TriCP-PhOEt as a ligand and transition the contrast agent to the cellular cytoplasm. The planar geometry of Mn(III)TriCP-PhOEt allows for water coordination both above and below the paramagnetic center. Its accumulation in targeted cells would result in significant shortening of the longitudinal relaxation time $\left(T_{1}\right)$, thereby allowing Oatp1a1 and/or Oatp1b3expressing cells to appear bright on $T_{1}$-weighted magnetic resonance images. Molecules are not drawn to scale. 
A

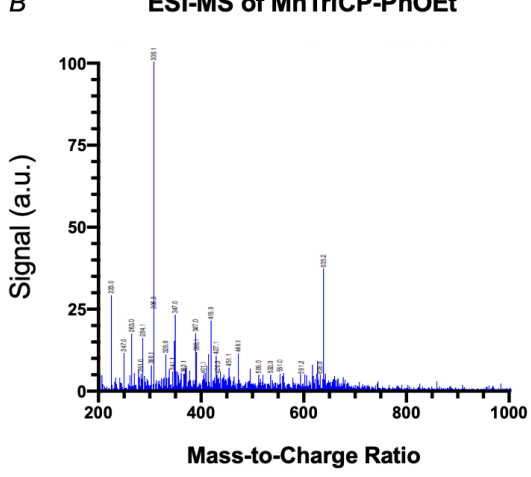

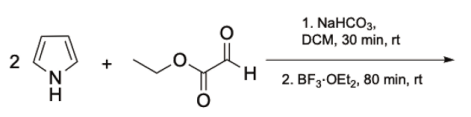

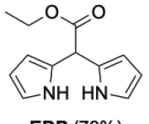

$\operatorname{EDP}(79 \%)$

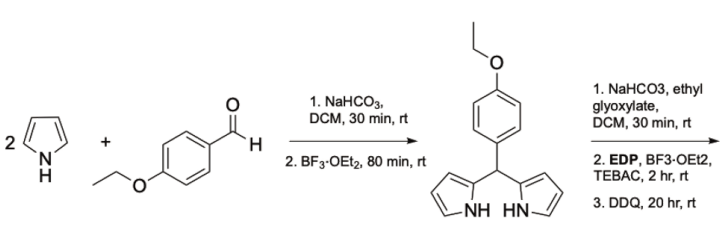

DPM-PhOEt (68\%)

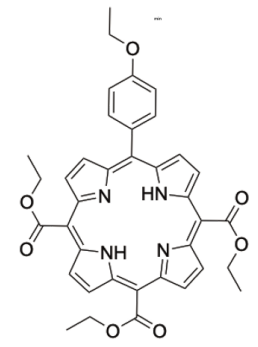

TriEP-PhOEt (23\%)

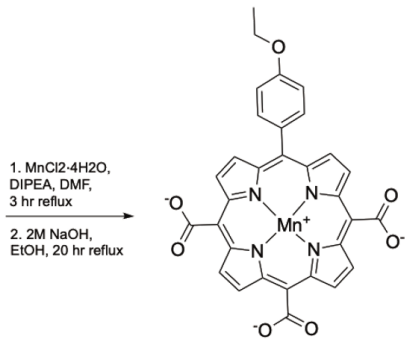

MnTriCP-PhOEt (83\%)
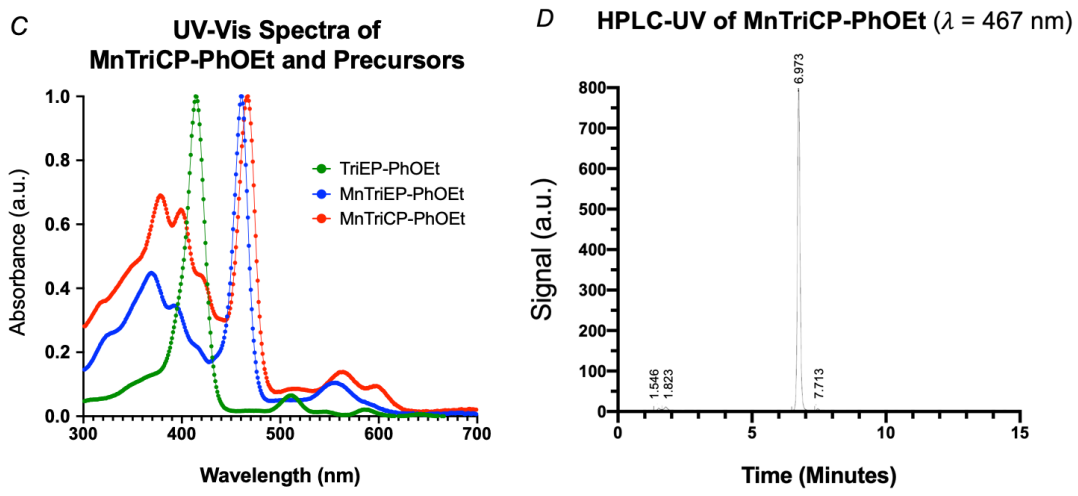

Figure 2. Synthesis and Validation of Mn(III)TriCP-PhOEt. A, Synthesis scheme for Manganese (III) 20-(4-ethoxyphenyl) porphyrin-5,10,15-tricarboxylate (MnTriCP-PhOEt). $\alpha$-1HPyrrol-2-yl-1H-pyrrole-2-acetic acid ethyl ester, EDP. 2,2'-(4-Ethoxyphenylmethylene) bis-1Hpyrrole, DPM-PhOEt. Triethyl 20-(4-ethoxyphenyl) porphyrin-5,10,15-tricarboxylate, TriEPPhOEt. B, Electrospray ionization mass spectrometry (ESI-MS) of Mn(III)TriCP-PhOEt, negative mode. Observed $m / z=306.1\left([\mathrm{M}]^{2-}\right)$. Calculated $m / z$ for $\mathrm{C}_{31} \mathrm{H}_{17} \mathrm{MnN}_{4} \mathrm{O}_{7}{ }^{2-}=306.03$. C, UV spectra of TriEP-PhOEt (green), Mn(III)TriEP-PhOEt (purple), and Mn(III)TriCP-PhOEt (red). D, HPLC-UV of Mn(III)TriCP-PhOEt, detected at $467 \mathrm{~nm}$. 
A Nuclear Magnetic Relaxation Dispersion Profiles $\left(0-1.5 \mathrm{~T}, 37^{\circ} \mathrm{C}\right)$

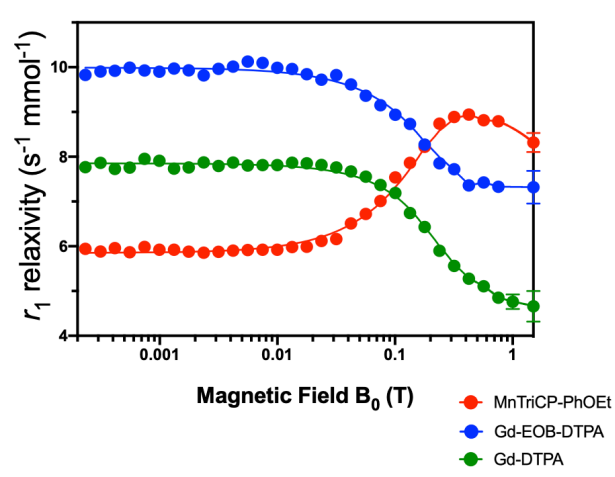

B $\quad R_{1} \operatorname{Map}\left(3 \mathrm{~T}, 18^{\circ} \mathrm{C}\right)$

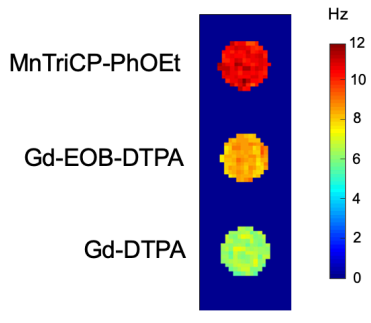

Figure 3. Paramagnetic Characterization of Mn(III)TriCP-PhOEt at Various Field Strengths. A, Nuclear magnetic relaxation dispersion profiles of $1 \mathrm{mM}$ solutions of $\mathrm{Mn}(\mathrm{III}) \mathrm{TriCP}-$ PhOEt (red), Gd(III)-EOB-DTPA (purple), and Gd(III)-DTPA (green) at $B_{0} \in(0,1.5) \mathrm{T}, 37^{\circ} \mathrm{C}$. Error bars indicate standard deviation. Cubic spline regressions are plotted for each contrast agent. $\mathrm{B}, R_{1}$ relaxation $(\mathrm{Hz})$ map of $1 \mathrm{mM}$ solutions of MnTriCP-PhOEt, Gd(III)-EOB-DTPA, and $\mathrm{Gd}(\mathrm{III})$-DTPA at $B_{0}=3 \mathrm{~T}, 18^{\circ} \mathrm{C}$. 
A

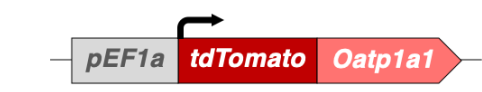

C

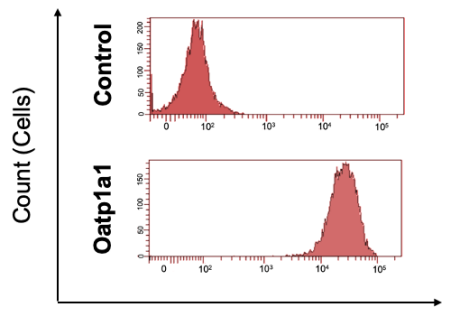

544/581 Fluorescence Intensity (RFUs)

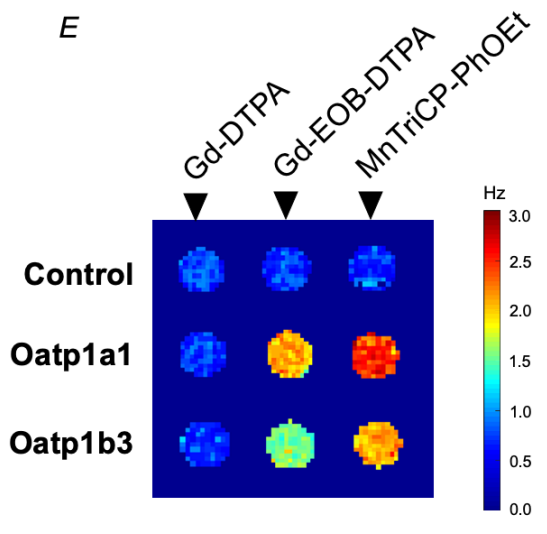

$B$
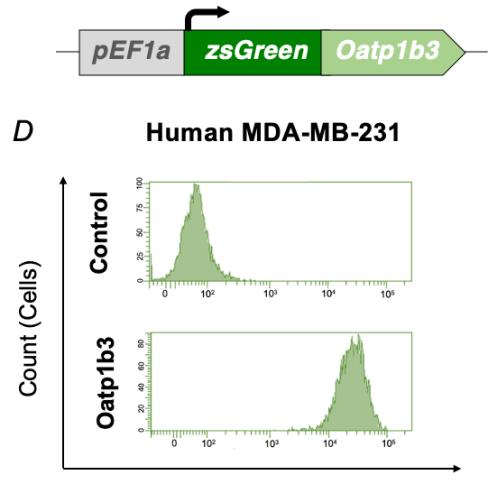

493/505 Fluorescence Intensity (RFUs)

F Spin-lattice Relaxation Rates of Engineered Cells (3 T)

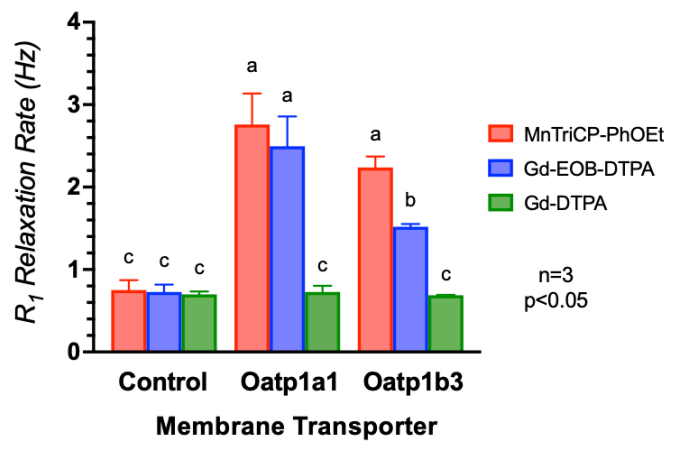

Figure 4. Mn(III)TriCP-PhOEt Increases in Spin-Lattice Relaxation Rates of Cells Expressing Oatp1a1 and Oatp1b3 Liver Transporters. C6 rat glioma cells were engineered to express the rat liver transporter Oatpla1 with tdTomato (A) and human breast cancer cells (MDAMB-231) were engineered to express the human liver transporter Oatp1b3 with zsGreen (B). Flow cytometry of control and engineered rat cells (C) and human cells (D) exhibiting pure populations of transporter-expressing cells. RFU, relative fluorescent units. Maps of spin-lattice relaxation rates $(\mathrm{Hz})$ for control, Oatp1a1-expressing, and Oatp1b3-expressing cells incubated with either Gd(III)-DTPA, Gd(III)-EOB-DTPA, or Mn(III)TriCP-PhOEt for 1 hour were acquired at 3 Tesla (E). Average spin-lattice relaxation rates $(\mathrm{Hz})$ of cells treated with contrast agents $(n=3)$ were computed from relaxation rate maps (F). Error bars indicate one standard deviation. 

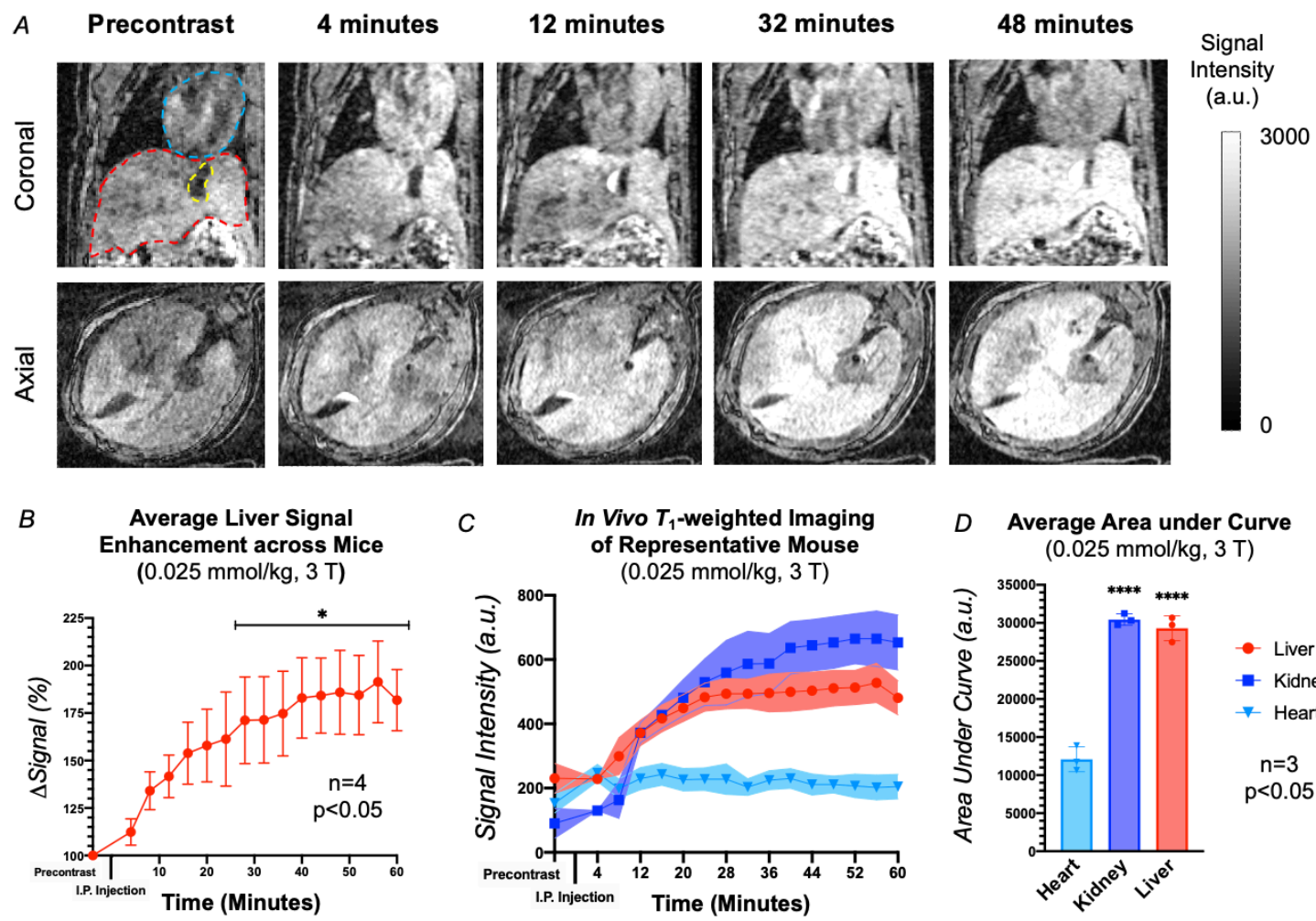

E
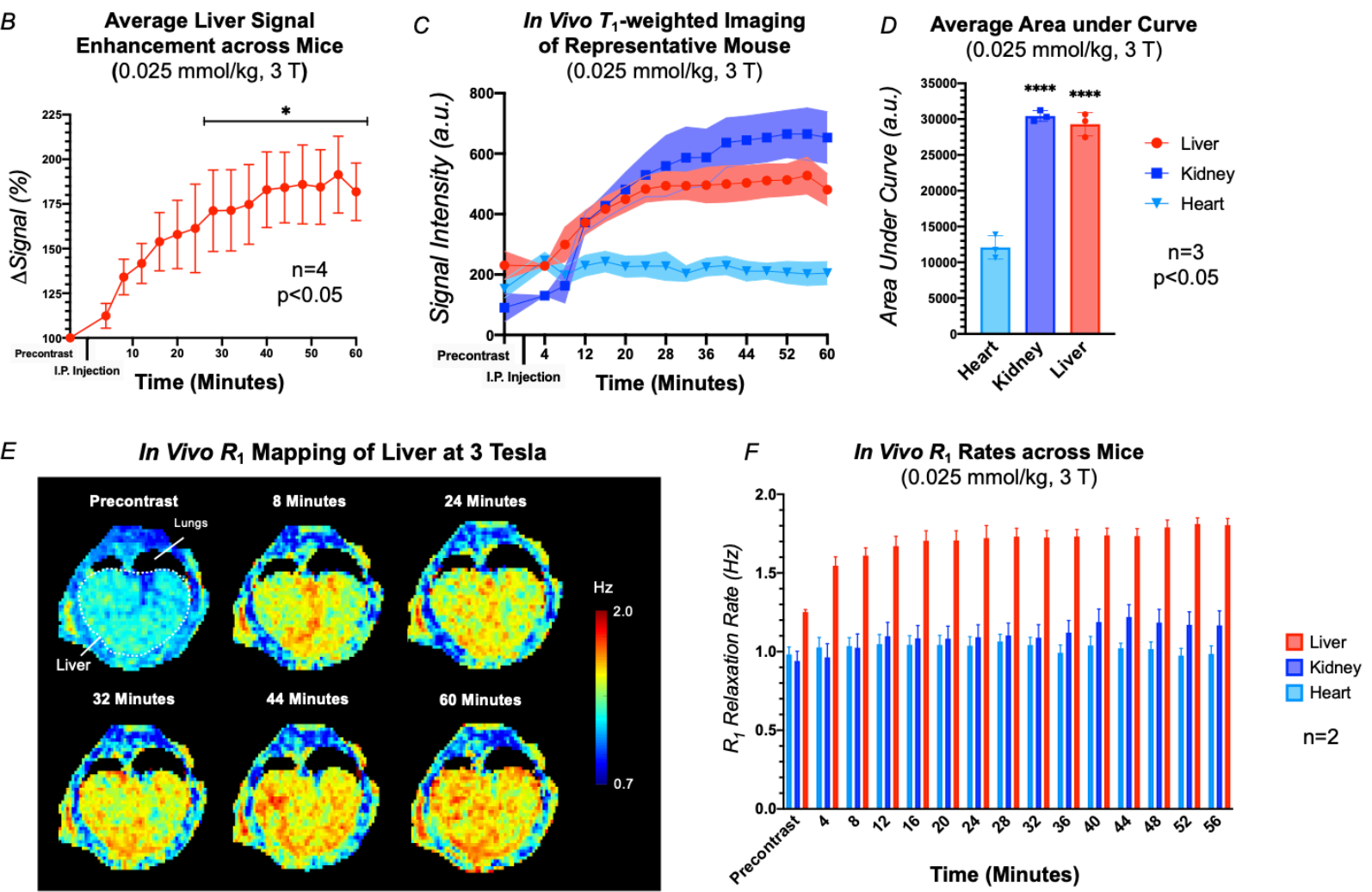

Figure 5. $T_{1}$-weighted and Quantitative Liver Imaging in Mice with $0.025 \mathrm{mmol} / \mathrm{kg}$ Mn(III)TriCP-PhOEt at 3 Tesla. A, $T_{1}$-weighted images of representative mouse before and following injection of $0.025 \mathrm{mmol} / \mathrm{kg} \mathrm{Mn}(\mathrm{III})$ TriCP-PhOEt. B, Signal intensity, arbitrary units (a.u.). C, Dynamic signal intensity curves of liver (red), kidney (purple), and heart (blue) tissue of representative mouse before and following injection of $0.025 \mathrm{mmol} / \mathrm{kg} \mathrm{Mn}$ (III)TriCP-PhOEt. Error bars represent standard deviation. D, Average change in signal intensity of liver tissue following injection of $0.025 \mathrm{mmol} / \mathrm{kg} \mathrm{Mn}$ (III)TriCP-PhOEt, in reference to pre contrast value $(\mathrm{n}=4, * * * * \mathrm{p}<0.0001)$. E, Representative in vivo $R_{1}$ map of axial cross-section of mouse before and following injection of $0.025 \mathrm{mmol} / \mathrm{kg} \mathrm{Mn}(\mathrm{III})$ TriCP-PhOEt, measured in hertz (Hz). F, Average in vivo longitudinal relaxation rate $(\mathrm{Hz})$ of various tissues before and following intraperitoneal injection of $0.025 \mathrm{mmol} / \mathrm{kg} \mathrm{Mn}(\mathrm{III})$ TriCP-PhOEt. Error bars represent standard error of the mean $(n=2)$. 


\section{$A$}
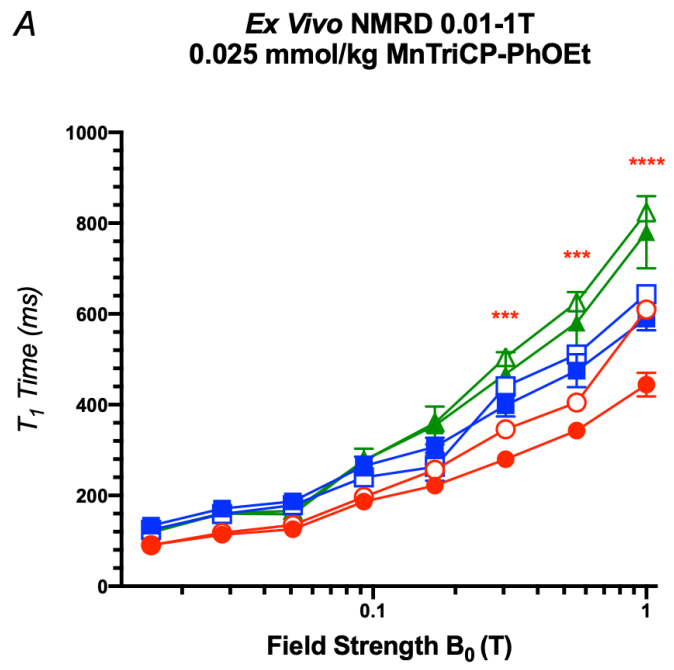

$B$

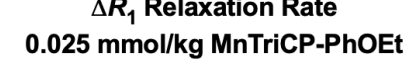

$B_{0}(T)$
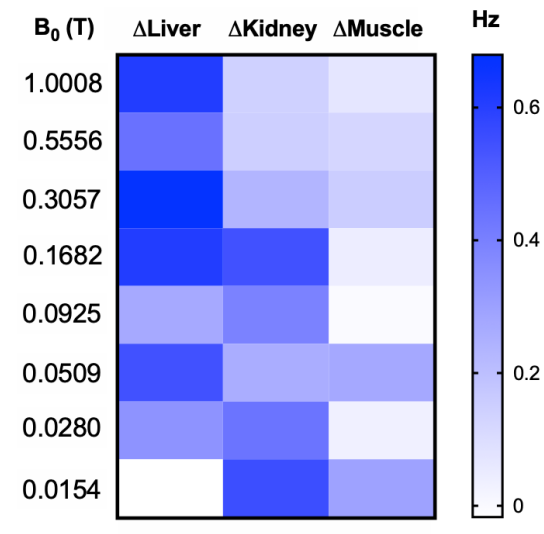

Figure 6. Ex Vivo Nuclear Magnetic Relaxation Dispersion of Various Tissues following Mn(III)TriCP-PhOEt Administration. A, Nuclear magnetic relaxation dispersion (NMRD) profiles of tissues from mice $(n=3)$ collected 36 minutes following intraperitoneal injection of $0.025 \mathrm{mmol} / \mathrm{kg} \mathrm{Mn}$ (III)TriCP-PhOEt or saline (control) acquired at low field. B, Heat map of differences in spin-lattice relaxation rates $(\mathrm{Hz})$ between mice administered $\mathrm{Mn}(\mathrm{III})$ TriCP-PhOEt or saline. 


\section{SUPPORTING INFORMATION}

Chemical Reagents and Instrumentation. All reagents and solvents were of commercial reagent grade and were used without further purification except where noted. Pyrrole, 4ethoxybenzaldehyde, 4-methoxybenzaldehyde, $\mathrm{BF}_{3} \bullet \mathrm{OEt}_{2}$, TEBAC, $\mathrm{MnCl}_{2} \bullet 4 \mathrm{H}_{2} \mathrm{O}$ and DCM were obtained from Sigma Aldrich (St. Louis, Missouri, USA). DDQ was obtained from AK Scientific, Inc. (Union City, California, USA). Ethyl glyoxylate was obtained from Alfa Aesar (Haverhill, Massachusetts, USA). $\mathrm{NaHCO}_{3}$ was obtained from Caledon Laboratories, Ltd. (Georgetown, Ontario, Canada). DIPEA was purchased from Acros Organics (Fair Lawn, New Jersey, USA). HEPES buffer ( $25 \mathrm{mM}, \mathrm{pH} 7.4$ ) fixed at the ionic strength of $0.1 \mathrm{M}$ using $\mathrm{NaCl}$ was used for all measurements. All other reagents and solvents were purchased from Fischer Scientific Inc. (Hampton, New Hampshire, USA). Thin layer chromatography (TLC) was performed using TLC silica gel 60 F254 plates from Merck Group (Darmstadt, Germany). Column chromatography was set up using Silica Gel 60, 250-400 microns from Desican Inc. (Scarborough, Ontario, Canada). Cation ion exchange was performed using an Amberlite ${ }^{\circledR}$ IR120, H resin (Sigma Aldrich). Dialysis was performed by use of Spectra/Por® 3 Dialysis membrane 1K MWCO (Fischer Scientific Inc.).

a-1H-Pyrrol-2-yl-1H-pyrrole-2-acetic acid, ethyl ester (EDP). The reaction was carried out in the dark under room temperature. $10 \mathrm{~g}(120 \mathrm{mmol}) \mathrm{NaHCO}_{3}$ was mixed with $100 \mathrm{~mL} \mathrm{DCM}$ under argon for 20 minutes. $20 \mathrm{~mL}(287 \mathrm{mmol})$ distilled pyrrole and $4 \mathrm{~mL}(20.2 \mathrm{mmol})$ ethyl glyoxylate $(50 \% \mathrm{v} / \mathrm{v}$ in toluene) was then added and stirred for 30 minutes. After TLC confirmation of full formation of intermediate alcohol product, the mixture was vacuum filtered to remove $\mathrm{NaHCO}_{3} .35 \mu \mathrm{L} \mathrm{BF} \cdot \mathrm{OEt}_{2}$ was then added along with $100 \mathrm{~mL}$ DCM and the mixture stirred for another 60 minutes. The crude product was washed with $100 \mathrm{~mL}$ saturated $\mathrm{NaHCO}_{3}$ and dried over $\mathrm{Na}_{2} \mathrm{SO}_{4}$. The solvent was removed under reduced pressure. The product was purified by column chromatography (silica gel, elution solvent $=7: 3 \mathrm{DCM} /$ Hexanes). $3.50 \mathrm{~g}$ (79.4\%) of EDP as a light pink solid was isolated. ${ }^{1} \mathrm{H}-\mathrm{NMR}(500 \mathrm{MHz}, \mathrm{CDCl} 3): \delta=8.46(\mathrm{~s}, 2 \mathrm{H}$, $-\mathrm{NH}), 6.72$ (q, 2H, pyrrole- $\alpha \mathrm{H}), 6.16$ and 6.08 (q, 4H, pyrrole- $\beta \mathrm{Hs}), 5.5(\mathrm{~s}, 1 \mathrm{H},-\mathrm{CH}), 4.23$ (q, $\left.2 \mathrm{H},-\mathrm{CH}_{2}\right)$ and $1.31\left(\mathrm{t}, 3 \mathrm{H},-\mathrm{CH}_{3}\right)$.

2,2'-(4-Ethoxyphenylmethylene)bis-1H-pyrrole (DPM-PhOEt). The reaction was carried out in the dark under room temperature. $0.67 \mathrm{~mL}(4.8 \mathrm{mmol})$ 4-ethoxybenzaldehyde was mixed with $2.43 \mathrm{~g}(28.9 \mathrm{mmol}) \mathrm{NaHCO}_{3}$ in $25 \mathrm{~mL} \mathrm{DCM}$ for 20 minutes under argon atmosphere. $5 \mathrm{~mL}$ (72 mmol) distilled pyrrole was then added and stirred for 30 minutes. After TLC confirmation of full formation of intermediate alcohol product, the mixture was vacuum filtered to remove $\mathrm{NaHCO}_{3} .32 \mu \mathrm{L} \mathrm{BF}_{3} \cdot \mathrm{OEt}_{2}$ was then added along with $25 \mathrm{~mL}$ DCM and the mixture stirred for another 70 minutes. The crude product was washed with $100 \mathrm{~mL}$ saturated $\mathrm{NaHCO}_{3}$, and dried over $\mathrm{Na}_{2} \mathrm{SO}_{4}$. The solvent was removed under reduced pressure and remaining pyrrole removed by vacuum distillation. The product was purified by column chromatography (silica gel, elution solvent $=$ 9:1 Hexanes/Acetone). $0.867 \mathrm{~g}(67.9 \%)$ of DPM-PhOEt as a yellow-pink solid was isolated. ${ }^{1} \mathrm{H}-\mathrm{NMR}(500 \mathrm{MHz}, \mathrm{DMSO}-\mathrm{d} 6): \delta=10.50(\mathrm{~s}, 2 \mathrm{H},-\mathrm{NH}), 6.82-7.03(\mathrm{dd}, 4 \mathrm{H}$, benzene $\mathrm{H}), 6.58(\mathrm{~m}, 2 \mathrm{H}$, pyrrole- $\alpha \mathrm{H}), 5.88(\mathrm{~m}, 2 \mathrm{H}$, pyrrole- $\beta \mathrm{H}), 5.62(\mathrm{~m}, 2 \mathrm{H}$, pyrrole- $\beta \mathrm{H}), 5.27(\mathrm{~s}, 1 \mathrm{H},-$ $\mathrm{CH}), 3.97\left(\mathrm{q}, 2 \mathrm{H},-\mathrm{OCH}_{2}-\right), 1.29\left(\mathrm{t}, 3 \mathrm{H},-\mathrm{CH}_{3}\right)$. 
Triethyl 20-(4-ethoxyphenyl)porphyrin-5,10,15-tricarboxylate (TriEP-PhOEt). The reaction was carried out in the dark at room temperature. $867.2 \mathrm{mg}(3.3 \mathrm{mmol})$ DPM-PhOEt was mixed with $1.29 \mathrm{~mL}(6.5 \mathrm{mmol})$ ethyl glyoxylate, $821 \mathrm{mg}(9.8 \mathrm{mmol}) \mathrm{NaHCO} 3$ and $4.4 \mathrm{~mL} \mathrm{DCM}$ under argon atmosphere for 2 hours. The intermediate dicarbinol product was confirmed by TLC, and the $\mathrm{NaHCO}_{3}$ was removed via vacuum filtration. The dark red intermediate was mixed with $711.5 \mathrm{mg}$ (3.3 mmol) EDP and $24 \mathrm{mg}$ TEBAC in $1400 \mathrm{~mL}$ DCM and stirred under argon for 50 minutes, after which $65 \mu \mathrm{L} \mathrm{BF}_{3} \cdot \mathrm{OEt}_{2}$ was then added. After an additional 50 minutes of stirring, $3.31 \mathrm{~g}$ (14.6 mmol) DDQ was then added, and the mixture was allowed to stir overnight. The dark purple-green crude was concentrated by rotary evaporation followed by filtration using a double-layer silica/alumina column, washed with 8:2 DCM/ethyl acetate. The filtered solution was then purified by column chromatography (silica gel, elution solvent $=99: 1 \mathrm{DCM} / \mathrm{ethyl}$ acetate). The semi-purified product was then centrifuged in 8:2 hexanes/ethyl acetate and the pellet collected to afford $484.5 \mathrm{mg}(23.0 \%)$ dark purple powder of TriEP-PhOEt. ${ }^{1} \mathrm{H}-\mathrm{NMR}(500$ $\mathrm{MHz}, \mathrm{CDCl} 3): \delta=9.52(\mathrm{~s}, 4 \mathrm{H}$, pyrrole- $\beta \mathrm{H}), 9.38(\mathrm{~d}, 2 \mathrm{H}$, pyrrole- $\beta \mathrm{H}), 8.99$ (d, $2 \mathrm{H}$, pyrrole- $\beta \mathrm{H})$, $8.09(\mathrm{~d}, 2 \mathrm{H}$, benzene $\mathrm{H}), 7.32\left(\mathrm{~m}, 2 \mathrm{H}\right.$, benzene $\mathrm{H}$ ), 5.07-5.13 (overlapping $\mathrm{q}, 6 \mathrm{H}$, ester $-\mathrm{OCH}_{2}-$ ), 4.33-4.37 (q, 2H, ether - $\mathrm{OCH}_{2}-$ ), 1.78-1.84 (overlapping t, $9 \mathrm{H}$, ester $\left.-\mathrm{CH}_{3}\right), 1.56-1.66(\mathrm{t}, 3 \mathrm{H}$, ether $\left.-\mathrm{CH}_{3}\right),-3.06(\mathrm{~s}, 2 \mathrm{H},-\mathrm{NH})$.

Manganese (III) triethyl 20-(4-ethoxyphenyl)porphyrin-5,10,15-tricarboxylate (MnTriEPPhOEt). $198.5 \mathrm{mg}$ (0.307 mmol) of TriEP-PhOEt was dissolved with $0.37 \mathrm{~mL}(2.2 \mathrm{mmol})$ DIPEA and $1.445 \mathrm{~g}$ ( $7.3 \mathrm{mmol}) \mathrm{MnCl}_{2} \bullet 4 \mathrm{H}_{2} \mathrm{O}$ in $20 \mathrm{~mL}$ of DMF. The mixture was refluxed for 2 hours. The reaction was then stopped and allowed to stir in air for another 2 hours. DMF was removed under reduced pressure, and the crude product was purified by column chromatography ( silica gel, elution solvent $=9.5: 0.5 \mathrm{DCM} / \mathrm{methanol}$ ) to afford 225.8 $\mathrm{mg}$ of MnTriEP-PhOEt. ESI-MS (positive mode, methanol) found $\mathrm{m} / \mathrm{z}=699.2\left([\mathrm{M}]^{+}\right)$; calculated for $\mathrm{C}_{37} \mathrm{H}_{32} \mathrm{MnN}_{4} \mathrm{O}_{7}^{+}$ $(\mathrm{m} / \mathrm{z}=699.16)$.

Manganese (III) 20-(4-ethoxyphenyl)porphyrin-5,10,15-tricarboxylate (MnTriCP-PhOEt). $225.8 \mathrm{mg}(0.307 \mathrm{mmol})$ of MnTriEP-PhOEt was dissolved in $45 \mathrm{~mL}$ ethanol and $35 \mathrm{~mL}$ THF. A $75 \mathrm{~mL}$ solution of $2 \mathrm{M} \mathrm{NaOH}$ was added to the mixture. The solution was refluxed for 24 hours with HPLC monitoring. The organic solvents were then removed under reduced pressure, and the crude product washed with ethyl acetate $(5 \times 100 \mathrm{~mL})$. The aqueous mixture was acidified with $1 \mathrm{M} \mathrm{HCl}$ to $\mathrm{pH} 2.00$ followed by centrifugation to remove the supernatant. Dialysis was carried out (MWCO $1 \mathrm{~K})$ on the pellet. Crude 5 was then passed through a cation exchange column (stationary phase: Amberlite ${ }^{\circledR}$ IR120 H resin, mobile phase: double distilled $\mathrm{H}_{2} \mathrm{O}$ ) to remove excess $\mathrm{Mn}(\mathrm{II})$ salts, and the product lyophilized. $175.4 \mathrm{mg}(82.7 \%)$ of brown powder was collected as MnTriCP-PhOEt. ESI-MS (negative mode, $\mathrm{H}_{2} \mathrm{O}$ ) found $\mathrm{m} / \mathrm{z}=306.0$ $\left([\mathrm{M}]^{2-}\right)$; calculated for $\mathrm{C}_{31} \mathrm{H}_{17} \mathrm{MnN}_{4} \mathrm{O}_{72}{ }^{-}(\mathrm{m} / \mathrm{z}=306.02)$.

Nuclear magnetic dispersion and magnetic resonance profiles. Contrast agents were first reconstituted in dimethyl sulfoxide (DMSO), warmed to $37^{\circ} \mathrm{C}$ and then diluted in Dulbecco's Modified Eagle Media (DMEM, Wisent Inc., Saint-Jean-Baptiste, Quebec, Canada) supplemented with $10 \%$ fetal bovine serum (FBS) to a final working concentration of $1 \mathrm{mM}$. Spin-lattice relaxation times were acquired at magnetic fields from $230 \mu \mathrm{T}$ to $1 \mathrm{~T}$ on a fast field-cycling NMR relaxometer (SpinMaster FFC2000 1T C/DC, Stelar, s.r.l., Mede, Italy) by changing the relaxation field in 30 steps, logarithmically distributed using an acquisition field of $380.5 \mathrm{mT}$, with 
temperature kept constant at $25^{\circ} \mathrm{C}$. Data for each contrast agent was subsequently fit into a LOWLESS spline curve with 10 points in the smoothing window. To determine relaxation rates at higher field strengths, an inversion recovery experiment was performed on a 1.5-Tesla GE CVMR and a 3-Tesla GE MR750 clinical scanner (General Electric Healthcare, Milwaukee Wisconsin, USA) using a 32-channel phase array head coil (General Electric Healthcare, Milwaukee Wisconsin, USA). A Fast Spin Echo Inversion Recovery (FSE-IR) pulse sequence was used with the following parameters: matrix size $=256 \times 256$, repetition time $(\mathrm{TR})=5000 \mathrm{~ms}$, echo time $(\mathrm{TE})=19.1 \mathrm{~ms}$, echo train length $=4$, number of excitations $=1$, receiver bandwidth $=12.50$ $\mathrm{kHz}$, inversion times $(\mathrm{TI})=20,35,50,100,125,150,175,200,250,350,500,750,1000,1500$, $2000,2500,3000$, in-plane resolution $=0.27 \mathrm{~mm}^{2}$, slice thickness $=2.0 \mathrm{~mm}$. Spin-lattice relaxation rates were computed via MatLab (R2020a, MathWorks, Natick, Massachusetts, USA) by calculating the signal intensity pixelwise across the inversion time image series, followed by nonlinear least-squares fitting of the data to the following equation to output the spin-lattice relaxation time $\left(T_{1}\right)$ :

\section{Equation 1. $S=\left|M_{S S}-\left(M_{S S}-M_{i}\right) \cdot e^{-T I / T_{1}}\right|$}

where $S, M_{S S}$, and $M_{i}$ represent the acquired signal, the longitudinal magnetization in steady state equilibrium, and the initial longitudinal magnetization acquired after the inversion pulse respectively.

Generation of stable cells expressing rat Oatp1a1 and human Oatp1b3 transporters. Human embryonic kidney cells (HEK 293T), human triple negative breast cancer cells (MDA-MB-231), and rat glioma cells (C6) were obtained from a commercial supplier (American Type Culture Collection; ATCC, Manassas, Virginia, USA) and cultured in Dulbecco's Modified Eagle Media (DMEM, Wisent Inc., Saint-Jean-Baptiste, Quebec, Canada) supplemented with $10 \%$ fetal bovine serum at $37^{\circ} \mathrm{C}$ and $5 \% \mathrm{CO}_{2}$. Cells were routinely tested for mycoplasma using the MycoAlert mycoplasma detection kit (Lonza Group, Basel, Switzerland). Lentiviral production involved third-generation packaging and envelope-expression plasmids (pMDLg/pRRE, pRSV-Rev, and pMD2.G, Addgene plasmids: \#12251,\#12253, and \#12259, respectively; gifts from Didier Trono). Lentiviral transfer plasmids were synthesized to encode $t d$ Tomato and rat-derived organic aniontransporting polypeptide 1 al for preclinical liver imaging or zsGreenl and human-derived organic anion-transporting polypeptide $1 b 3$ to assess clinical translation of MnTriCP-PhOEt, all under regulation of the human elongation factor 1 alpha promoter $(\mathrm{pEF} 1 \alpha)$. To produce Oatplal- and Oatp1b3-encoding lentiviruses (LV-Oatp1a1 and LV-Oatp1b3, respectively), packaging, envelope and the relevant transfer plasmid were co-transfected into HEK 293T cells using Lipofectamine 3000 according to the manufacturer's lentiviral production protocol (Thermo Fisher Scientific Inc., Waltham, Massachusetts, USA). Lentivirus-containing supernatants were harvested $24 \mathrm{~h}$ and $48 \mathrm{~h}$ post transfection, filtered through a $0.45-\mu \mathrm{m}$ filter, and stored at $-80^{\circ} \mathrm{C}$ prior to use. Rat $\mathrm{C} 6$ cells were transduced with lentivirus encoding tdTomato and rat-derived organic anion-transporting polypeptide lal (LV-tdT/FLuc/Oatpla1) overnight in the presence of 4- to $8-\mu \mathrm{g} / \mathrm{mL}$ polybrene. Human MDA-MB-231 cells were transduced with lentivirus encoding zsGreen1 and humanderived organic anion-transporting polypeptide $1 b 3$ (LV-zsG/Oatp1b3) following the same protocol. Transduced cells were washed, collected, and sorted using a FACSAria III fluorescenceactivated cell sorter (BD Biosciences, Mississauga, Ontario, Canada) for either tdTomato and/or zsGreen 1 fluorescence. 
Measuring relaxation rates of Oatp1-expressing cells incubated with MnTriCP-PhOEt. Nontransduced and Oatp1a1-expressing C6 cells, and non-transduced and Oatp1b3-expressing MDAMB-231 cells were each seeded in T-175 flasks $\left(2 \times 10^{6}\right)$ and grown for 3 days. Cells were trypsinized and suspended in $2 \mathrm{~mL}$ of DMEM containing either $1 \mathrm{mM} \mathrm{Gd(III)-EOB-DTPA}$ (Eovist/Primovist ${ }^{\circledR}$, Bayer Health Care Pharma, Berlin, Germany), $1 \mathrm{mM}$ Gd(III)-DTPA (Magnevist ${ }^{\circledR}$, Bayer Schering Pharma, Berlin, Germany), or $1 \mathrm{mM}$ MnTriCP-PhOEt for 60 minutes. Cells were centrifuged and washed three times with DMSO (30\% v/v) in PBS to remove contrast agent remaining in the extracellular compartment, after which, $3 \times 10^{7}$ cells were pelleted into $0.2-\mathrm{ml}$ tubes, and then placed into a $1 \%$ agarose phantom. Inversion recovery images were acquired through a cross section of the tubes in the agarose phantom to measure spin-lattice relaxation rates of each cell condition, using the imaging parameters described above.

In vivo $\boldsymbol{T}_{1}$-weighted imaging and $\boldsymbol{R}_{1}$ mapping in mice at 3 Tesla. All animal experiments were performed in compliance with an approved protocol of the University of Western Ontario's Council on Animal Care (Animal Use Protocol 2016-026) and in accordance with the standards of the Canadian Council on Animal Care. Female nude mice ( $\mathrm{n}=9$ total, NU-Foxn ${ }^{n u}$ strain; Charles River Laboratories, Wilmington, Massachusetts, USA) were anesthetized with $1 \%-2 \%$ isoflurane by using a nose cone attached to an activated carbon charcoal filter for passive scavenging, and positioned in a lab-built tray that was warmed to $40^{\circ} \mathrm{C}$ during MR imaging. For all mice, a precontrast image was acquired, followed by a slow rate $(50 \mu \mathrm{L}$ per minute, $500 \mu \mathrm{L}$ volume total) intraperitoneal injection of $0.025 \mathrm{mmol} / \mathrm{kg}$ MnTriCP-PhOEt dissolved in 30\% v/v DMSO (30\% $\mathrm{v} / \mathrm{v}$ ) in saline and imaged for 60 minutes. All images were acquired on a clinical 3-Tesla GE MR750 clinical scanner (General Electric Healthcare, Milwaukee Wisconsin, USA), using a custom-built insert gradient [inner diameter $=17.5 \mathrm{~cm}$, gradient strength $=500 \mathrm{mT} / \mathrm{m}$, peak slew rate $=3000 \mathrm{~T} / \mathrm{m} / \mathrm{s}$, and a bespoke $3.5-\mathrm{cm}$ diameter, $5.0-\mathrm{cm}$ length birdcage radiofrequency coil (Morris Instruments, Ottawa, Ontario, Canada). $T_{1}$-weighted images were acquired $(\mathrm{n}=4)$ using a three-dimensional Fast Spoiled Gradient Echo (FSPGR) pulse sequence: frequency FOV $=4.0 \mathrm{~cm}$, phase $\mathrm{FOV}=2.6 \mathrm{~cm}$, slice thickness $=0.4 \mathrm{~mm}, \mathrm{TR}=12.0 \mathrm{~ms}, \mathrm{TE}=3.2 \mathrm{~ms}$, flip angle $=60^{\circ}$, matrix size $=128 \times 128$, number of excitations $=1$, receiver bandwidth $=31.25 \mathrm{kHz}$, acquisition time $=3: 52$ per image. To obtain $R_{1}$ maps of kinetic data $(\mathrm{n}=2)$, the driven equilibrium single pulse observation of $T_{1}$ (DESPOT1) approach ${ }^{[37]}$ was employed, using a $5^{\circ}$ and $20^{\circ}$ flip angle pair in an FSPGR pulse sequence: frequency $\mathrm{FOV}=4.0 \mathrm{~cm}$, phase $\mathrm{FOV}=2.6 \mathrm{~cm}$, slice thickness $=0.4 \mathrm{~mm}$, $\mathrm{TR}=6.9 \mathrm{~ms}, \mathrm{TE}=2.4 \mathrm{~ms}$, matrix size $=100 \times 100$, number of excitations $=5$, receiver bandwidth $=31.25 \mathrm{kHz}$, acquisition time $=3: 39$ per image. Pixelwise in vivo spin-lattice relaxation time maps for each timepoint were computed via MatLab (R2020a, MathWorks, Natick, Massachusetts, United States) by linking consecutive pairs of variable flip angle images and calculating the slope of their signal intensities according to the following equation:

\section{Equation 2.}

$$
\frac{S_{\alpha}}{\sin \alpha}=\frac{S_{\beta}}{\tan \beta} \times e^{-T R / T_{1}}+M_{0}\left(1-e^{-T R / T_{1}}\right)
$$

Where $S_{\alpha}$ is the FSPGR signal intensity associated with flip angle $\alpha, S_{\beta}$ is the FSPGR signal intensity associated with flip angle $\beta$, and $M_{0}$ is the proportionality constant relating to the equilibrium longitudinal magnetization. Plotting $\frac{S_{\alpha}}{\sin \alpha}$ against $\frac{s_{\beta}}{\tan \beta}$ for each pixel allows for the determination of $T_{1}$ from the slope $m$ of this line as: 
Equation 3. $\quad T_{1}=\frac{-T R}{\ln (m)}$

All resultant images were reconstructed and analyzed on open-source ITK-SNAP (Version 3.8.0) software ${ }^{[38]}$. Manual segmentation was performed for each mouse to create volumes-of-interest for the liver, both kidneys, and the heart, which were applied across pre-contrast and all post-contrast timepoints for each mouse to generate dynamic signal intensity (arbitrary units) or $T_{1}$ time (ms) curves. Mean signal intensity \pm standard deviation or mean $T_{1}$ time \pm standard deviation was then calculated for statistical testing.

Ex vivo nuclear magnetic relaxation dispersion. To validate in vivo $R_{1}$ calculations, a separate cohort of mice $(\mathrm{n}=3)$ were intraperitoneally injected with $0.025 \mathrm{mmol} / \mathrm{kg} \mathrm{MnTriCP}-\mathrm{PhOEt}$ dissolved in $30 \% \mathrm{v} / \mathrm{v}$ DMSO $(30 \% \mathrm{v} / \mathrm{v})$ in saline, or an equivalent volume of $30 \% \mathrm{v} / \mathrm{v}$ DMSO $(30 \% \mathrm{v} / \mathrm{v})$ in saline as a control. Forty-four minutes post-injection, mice were euthanized via isoflurane overdose and liver, kidney and muscle tissue were immediately harvested, gently rinsed with and placed in NMR tubes for low-field NMRD measurements. Spin-lattice relaxation rates $\left(R_{1} ; \mathrm{Hz}\right) \pm$ error were acquired for each organ at the following field strengths: 0.0154023, $0.0280061,0.0509018,0.0925129,0.1681517,0.3056599,0.555566$, and $1.0008455 \mathrm{~T}$ using a fast field-cycling NMR relaxometer (SpinMaster FFC2000 1T C/DC, Stelar, s.r.l., Mede, Italy) as described above. $R_{1}$ rates at each field strength were then averaged to determine statistical differences between MnTriCP-PhOEt and saline control mice.

Statistics. Unless otherwise stated, all statistical analyses were carried out using Graphpad Prism software (Version 9.00 for Mac OS X, GraphPad Software Inc., La Jolla, California, USA, www.graphpad.com). For NMRD profiles, cubic spline regression curves were calculated with 4 knots and 4960 output segments. One-way Analysis of Variance (ANOVA) was performed followed by Tukey's post-hoc multiple comparisons to determine statistical differences in longitudinal relaxation rates in vitro, in cellulo. and in vivo. For all tests, a nominal p-value less than 0.05 was considered statistically significant. 

available under aCC-BY-NC-ND 4.0 International license.

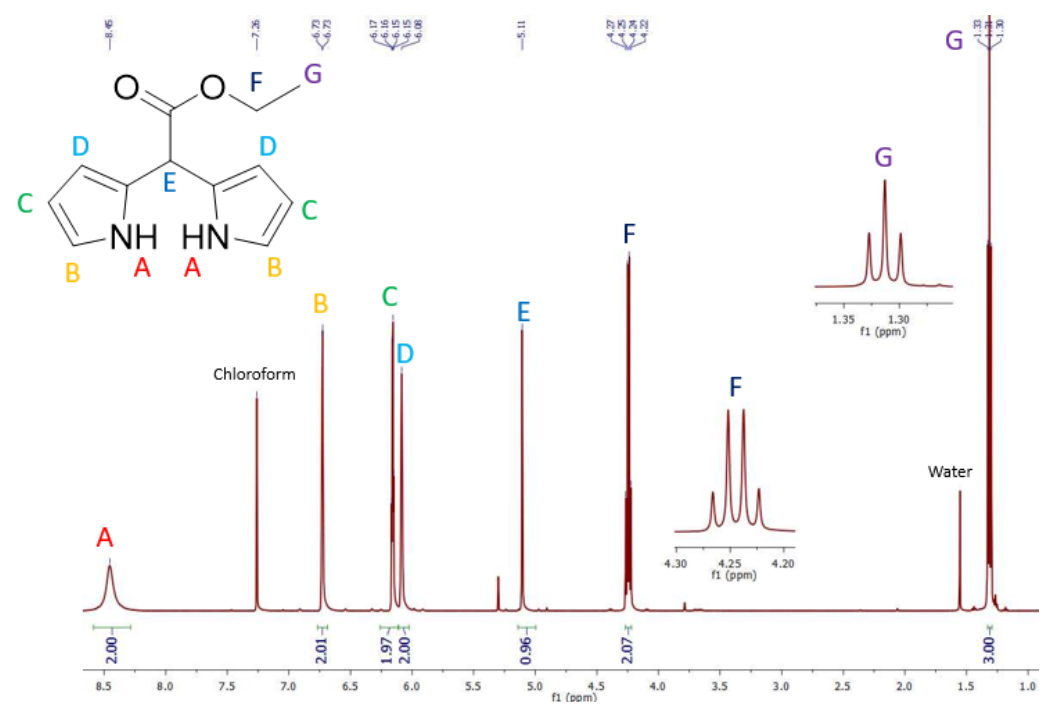

Supplementary Figure 1. ${ }^{1} \mathrm{H}-\mathrm{NMR}$ of EDP, a precursor to $\mathrm{Mn}(\mathrm{III}) \mathrm{TriCP}-\mathrm{PhOEt}$, in $\mathrm{CDCl}_{3}$. 


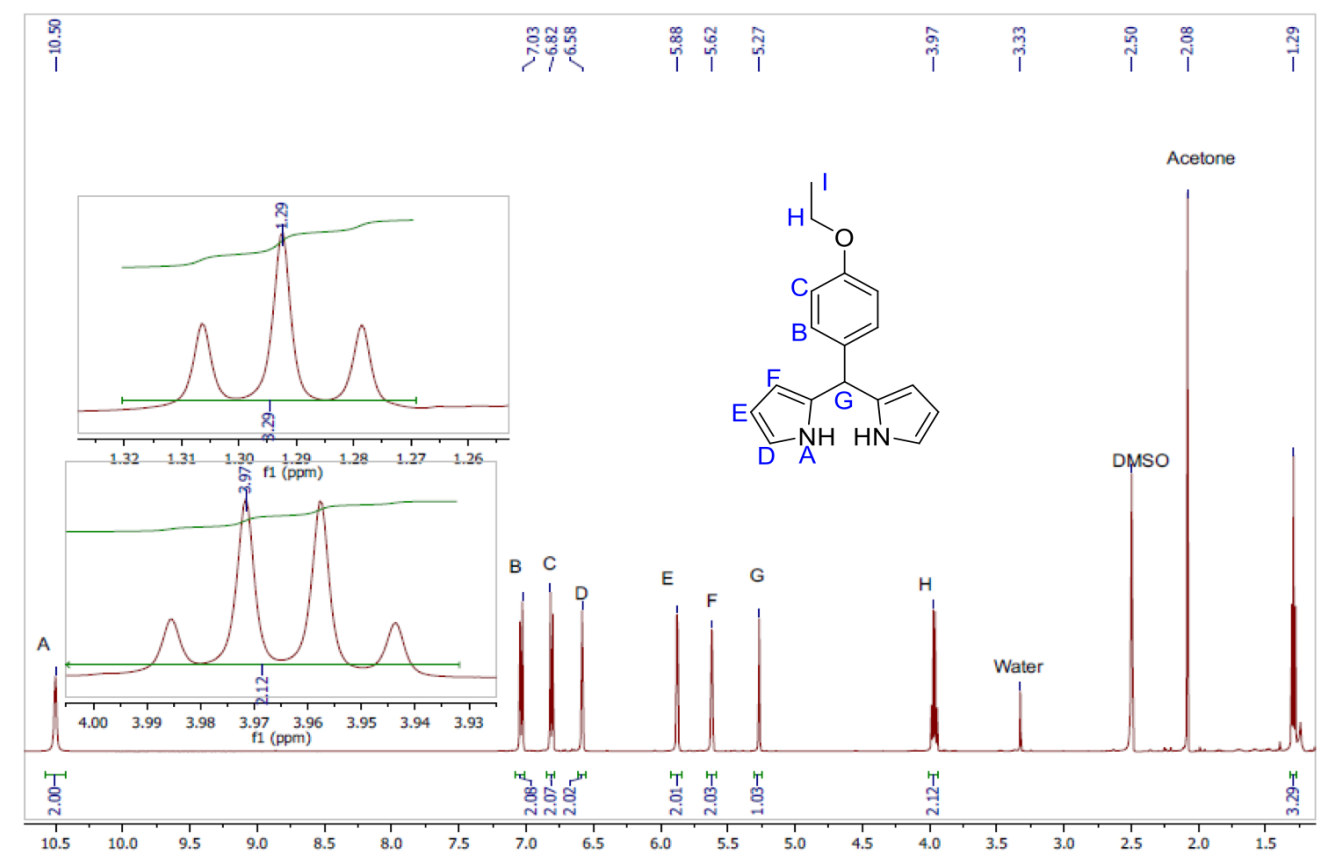

Supplementary Figure 2. ${ }^{1} \mathrm{H}-\mathrm{NMR}$ of DPM-PhOEt, a precursor to $\mathrm{Mn}(\mathrm{III}) \mathrm{TriCP}-\mathrm{PhOEt}$, in DMSO-d6. 


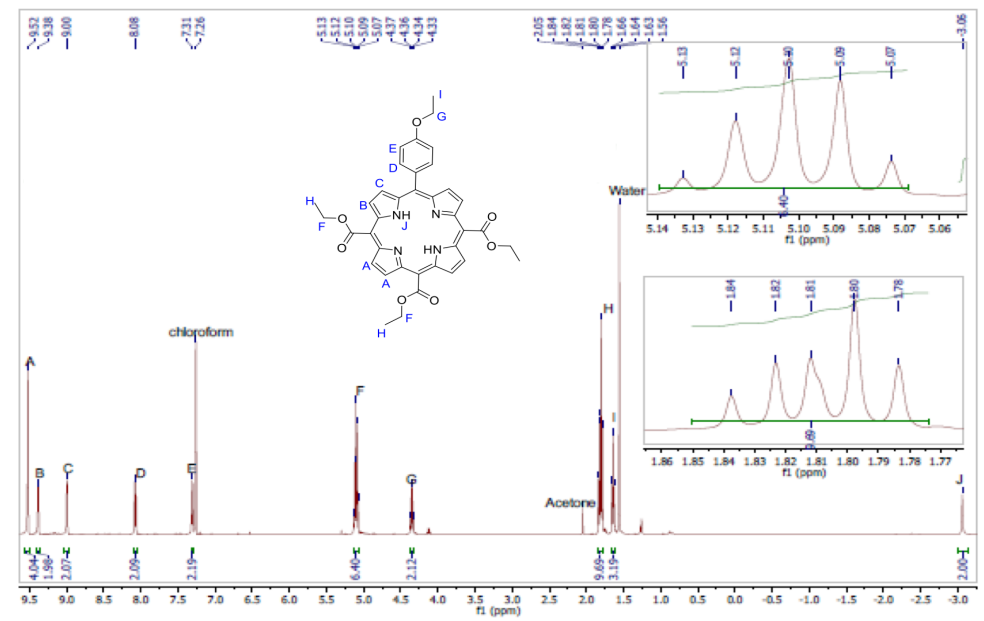

Supplementary Figure 3. ${ }^{1} \mathrm{H}-\mathrm{NMR}$ of TriEP-PhOEt, a precursor to Mn(III)TriCP-PhOEt, in $\mathrm{CDCl}_{3}$. 

available under aCC-BY-NC-ND 4.0 International license.

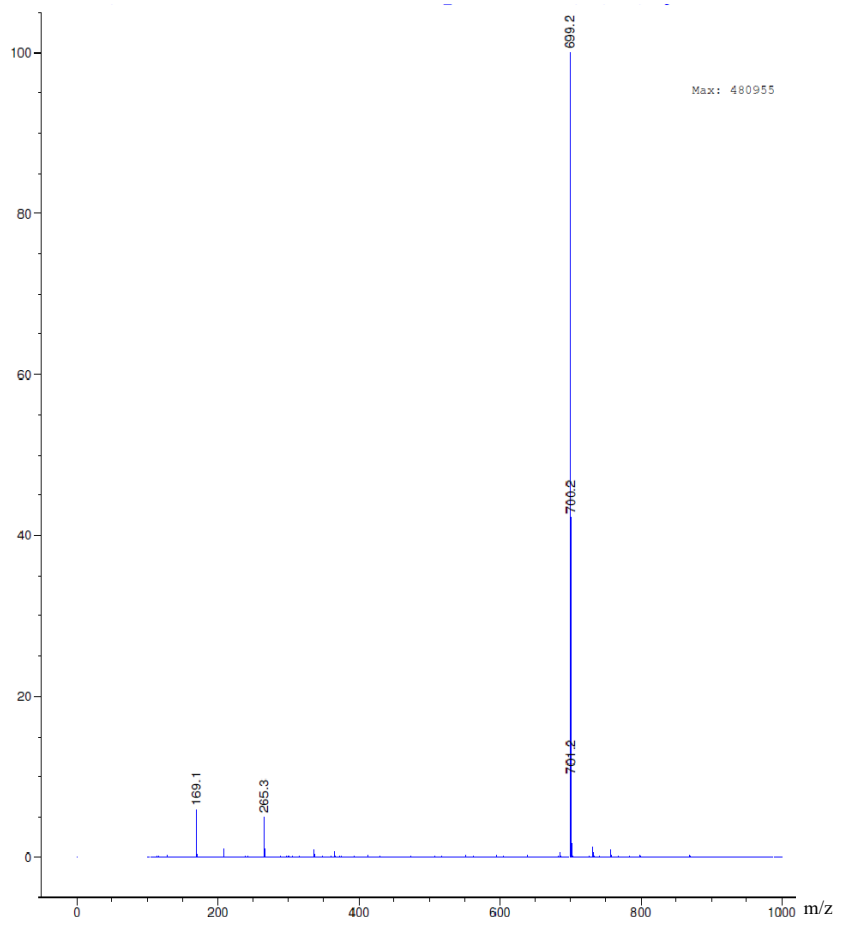

Supplementary Figure 4. ESI-MS of Mn(III)TriEP-PhOEt, positive mode. ESI-MS found $\mathrm{m} / \mathrm{z}=$ $699.2\left([\mathrm{M}]^{+}\right)$Calculated for $\mathrm{C}_{37} \mathrm{H}_{32} \mathrm{MnN}_{4} \mathrm{O}_{7}{ }^{+}, m / z=699.17$. 

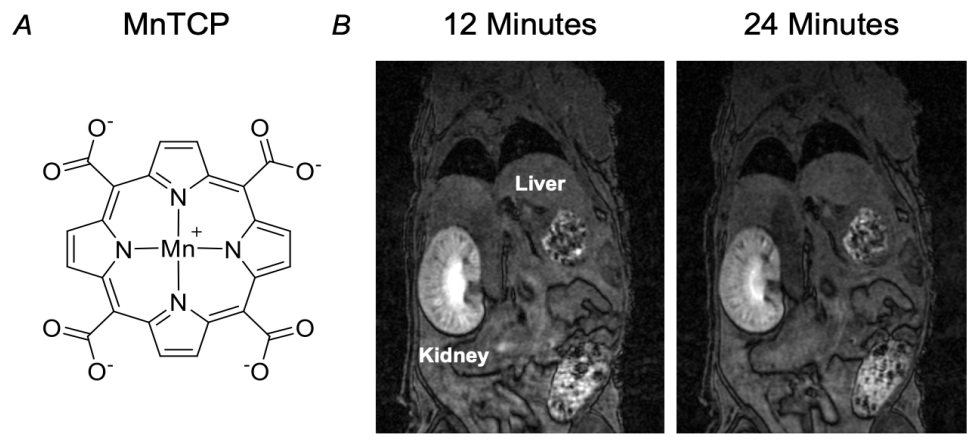

36 Minutes

Supplementary Figure 5. In vivo biodistribution of non-targeted manganese(III) porphyrin. A, Chemical structure of manganese(III) porphyrin-5,10,15,20-tetracarboxylate (MnTCP). B, $T_{1}$ weighted images of a female mouse acquired 12, 24, and 36 minutes post intravenous administration of $0.1 \mathrm{mmol} / \mathrm{kg} \mathrm{Mn}(\mathrm{III}) \mathrm{TCP}$ at 3 Tesla. 